NBER WORKING PAPER SERIES

MEASURING THE FINANCIAL SOPHISTICATION OF HOUSEHOLDS

\author{
Laurent E. Calvet \\ John Y. Campbell \\ Paolo Sodini \\ Working Paper 14699 \\ http://www.nber.org/papers/w14699
NATIONAL BUREAU OF ECONOMIC RESEARCH
1050 Massachusetts Avenue
Cambridge, MA 02138
February 2009

We thank Statistics Sweden for providing the data. This material is based upon work supported by the Agence Nationale de la Recherche under a Chaire d'Excellence to Calvet, BFI under a Research Grant to Sodini, the HEC Foundation, the National Science Foundation under Grant No. 0214061 to Campbell, Riksbank, and the Wallander and Hedelius Foundation. The views expressed herein are those of the author(s) and do not necessarily reflect the views of the National Bureau of Economic Research.

NBER working papers are circulated for discussion and comment purposes. They have not been peerreviewed or been subject to the review by the NBER Board of Directors that accompanies official NBER publications.

(C) 2009 by Laurent E. Calvet, John Y. Campbell, and Paolo Sodini. All rights reserved. Short sections of text, not to exceed two paragraphs, may be quoted without explicit permission provided that full credit, including $\left({ }^{\circ}\right.$ notice, is given to the source. 
Measuring the Financial Sophistication of Households

Laurent E. Calvet, John Y. Campbell, and Paolo Sodini

NBER Working Paper No. 14699

February 2009

JEL No. G11

\section{ABSTRACT}

This paper constructs an index of financial sophistication that, in comprehensive data on Swedish households, best explains a set of three investment mistakes: underdiversification, risky share inertia, and the tendency to sell winning stocks and hold losing stocks (the disposition effect). The index of financial sophistication increases strongly with financial wealth and household size, and to a lesser extent with education and proxies for financial experience. The index is strongly positively correlated with the share of risky assets held by a household.

Laurent E. Calvet

Department of Finance

HEC Paris

1 avenue de la Libération

78351 Jouy en Josas

France

and NBER

calvet@hec.fr

John Y. Campbell

Morton L. and Carole S.

Olshan Professor of Economics

Department of Economics

Harvard University

Littauer Center 213

Cambridge, MA 02138

and NBER

john_campbell@harvard.edu
Paolo Sodini

Department of Finance

Stockholm School of Economics

Sveavägen 65

Box 6501

SE-113 83 Stockholm

Sweden

Paolo.Sodini@hhs.se 


\title{
Measuring the Financial Sophistication of Households
}

\author{
By Laurent E. Calvet, John Y. Campbell, and PaOlo Sodini*
}

Many households invest in ways that are hard to reconcile with standard financial theory and that have been labelled as investment mistakes (Campbell, 2006; Calvet, Campbell and Sodini, henceforth "CCS", 2007). There is increasing interest among household finance researchers in the concept of financial sophistication, defined as the ability of a household to avoid making such mistakes. A growing empirical literature documents a cross-sectional correlation between household characteristics and investment mistakes. Richer, better educated households tend to be better diversified (Marshall Blume and Irwin Friend, 1975; CCS, 2007; William Goetzmann and Alok Kumar, 2008; Annette VissingJorgensen, 2003), display less inertia (Julie Agnew, Pierluigi Balduzzi, and Annika Sundén, 2003; Yannis Bilias, Dimitris Georgarakos and Michael Haliassos, 2008; Campbell, 2006; CCS, 2009; VissingJorgensen, 2002), and have a weaker disposition to hold losing and sell winning stocks (CCS, 2009; Ravi Dhar and Ning Zhu, 2006) than other households. One feature of these earlier papers is that mistakes are investigated one at a time, often on a nonrepresentative sample of households.

In this paper, we jointly analyze several investment mistakes in a comprehensive, high-quality panel of household finances. Because Swedish residents pay taxes on both income and wealth, Statistics Sweden has a parliamentary mandate to collect highly detailed

* Calvet: Department of Finance, HEC Paris, 1 avenue de la Libération, 78351 Jouy-en-Josas, France; and NBER, calvet@hec.fr. Campbell: Department of Economics, Littauer Center, Harvard University, Cambridge, MA 02138, USA, and NBER, john_campbell@harvard.edu. Sodini: Department of Finance, Stockholm School of Economics, Sveavägen 65, Box 6501, SE-113 83 Stockholm, Sweden, Paolo.Sodini@hhs.se. We thank Douglas Bernheim for helpful comments and suggestions, and Statistics Sweden for providing the data. This material is based upon work supported by the Agence Nationale de la Recherche under a Chaire d'Excellence to Calvet, BFI under a Research Grant to Sodini, the HEC Foundation, the National Science Foundation under Grant No. 0214061 to Campbell, Riksbank, and the Wallander and Hedelius Foundation. information on the finances of every household in the country. We compiled the data supplied by Statistics Sweden into a panel of the entire population (about 4.8 million households) covering four years (19992002). We observe detailed demographic and income information, and, most notably, the worldwide assets owned by each resident on December 31 of each year, including bank accounts, mutual funds and stocks. The information is provided for each individual account or each security referenced by its International Security Identification Number (ISIN). We refer the reader to CCS $(2007,2009)$ for a detailed presentation of this dataset.

We use the Swedish panel to simultaneously investigate three types of investment mistakes: underdiversification, inertia in risk taking, and the disposition effect in direct stockholdings. Consistent with earlier research, financial wealth, family size and education are found to have a negative impact on the level of all three mistakes. These findings motivate the construction of an index of financial sophistication, which is obtained by regressing the negative of the mistake vector on a single combination of household characteristics. The index of financial sophistication increases strongly with log financial wealth and household size, and to a lesser extent with education and proxies for financial experience. We briefly discuss how sophistication can be estimated in less detailed datasets. An Appendix available online further presents the dataset and the estimation methodology.

\section{Measuring Investment Mistakes}

\section{A. Definitions}

Following CCS (2007, 2009), we consider three classes of liquid financial assets, excluding illiquid assets from consideration. Cash consists of bank account balances and money market funds. Mutual funds refer to all other funds. Stocks refer to direct holdings only. We measure a household's financial wealth as the sum of its holdings in these asset classes. This definition focuses on gross wealth and does not subtract mortgage or other household debt. 
We define the following variables for each household $h$. The risky portfolio contains stocks and mutual funds but excludes cash. The risky share $w_{h, t}$ at date $t$ is the weight of the risky portfolio in financial wealth.

\section{B. Investment Mistakes}

For every household $h$, we denote by $y_{h, t}=$ $\left(y_{h, t, 1} ; y_{h, t, 2} ; y_{h, t, 3}\right)^{\prime}$ a vector of investment mistakes at date $t$. The first component $y_{h, t, 1}$ measures underdiversification, the second component $y_{h, t, 2}$ risky share inertia, and the third component $y_{h, t, 3}$ the disposition effect. The definition of these variables is now explained.

Since Sweden is a small and open economy, we assess the diversification of household portfolios relative to a global equity portfolio, the MSCI World Index. As in CCS (2007), we assume that assets are priced on world markets in an international currency according to a global version of the CAPM. From the perspective of a Swedish investor, the pricing model induces a domestic CAPM in which the currencyhedged world index is mean-variance efficient. Because currency-hedging is typically unavailable to most retail investors, except perhaps the richest, we view the unhedged version of the index as a more attainable benchmark. We therefore measure underdiversification in household $h$ 's risky portfolio by the relative Sharpe ratio loss

$$
y_{h, t, 1}=1-\frac{S_{h, t}}{S_{m}},
$$

where $S_{h, t}$ and $S_{m}$ respectively denote the Sharpe ratio of the risky portfolio and unhedged index under the CAPM.

In CCS (2009) we have developed a structural model of portfolio rebalancing, in which inertia can be measured by the instrumental variable regression of risky share changes on household characteristics. We now construct a proxy that can be readily computed from individual household data. A useful starting point is provided by the absolute value of risky share changes, $\left|w_{h, t}-w_{h, t-1}\right|$, which Vissing-Jorgensen (2002) uses as a measure of inertia. We have found in CCS (2009) that boundary effects are typically more pronounced in levels than in logs. For this reason, we proxy inertia by:

$$
y_{h, t, 2}=\left|\ln \left(w_{h, t}\right)-\ln \left(w_{h, t-1}\right)\right|,
$$

that is by the absolute value of risky share changes in logs

As in Terrance Odean (1998) and Dhar and Zhu (2006), our analysis of the disposition effect builds on the proportion of stock gains realized during the year, $P G R_{h, t}$, and the proportion of stock losses realized, $P L R_{h, t}$. A gain in a particular stock is counted as being realized if the investor sells some (but not necessarily all) of its holdings of the stock. The household's proportion of gains realized, $P G R_{h, t}$, is then defined as the number of winning stocks with realized gains divided by the total number of winning stocks. $P L R_{h, t}$ is defined analogously. The disposition effect in direct stockholdings is then measured by the difference:

$$
y_{h, t, 3}=P G R_{h, t}-P L R_{h, t} .
$$

We depart in two ways from the earlier literature. First, because the purchase price is unavailable in our dataset, we classify a stock as a winner if it has a higher return than the unhedged world index during the year, and as a loser if it underperforms the index.

Second, Dhar and Zhu (2006) focus on the set of households that have experienced both gains and losses in their stock portfolios. We are concerned that this restriction might bias the analysis towards households with large stock portfolios, so we look at a broader set of households that own stocks at the end of a given year $t$ and still hold risky assets at the end of the following year. We extend the definition of $P G R_{h, t}$ and $P L R_{h, t}$ to this broader set of investors. If the household does not experience a gain during the year, we set $P G R_{h, t}$ equal to the crosssectional mean for households with gains. Similarly if the household does not experience a loss during the year, we set $P L R_{h, t}$ equal to the cross-sectional mean for households with losses.

\section{Empirical Results}

\section{A. Unrestricted Regressions}

In Table 1, we report the results of the pooled regressions of each investment mistake on household characteristics:

$$
y_{h, t, j}=\beta_{j}^{\prime} x_{h, t}+\varepsilon_{h, t, j}, \quad 1 \leq j \leq 3,
$$

where all left-hand side and right-hand side variables are demeaned year by year. The vector $x_{h, t}$ contains both financial and demographic characteristics at the 
end of year $t-1$.. The first category includes disposable income, contributions to private pension plans as a fraction of a three-year average of disposable income, log financial wealth, log real estate wealth, log of total liabilities, and dummies for households that are retired, unemployed, self-employed ("entrepreneurs"), and students. The second category includes age, household size, and dummies for households that have high-school education, post-high-school education, or missing education data (most common among older and immigrant households) or are immigrants.

Financial wealth has a strikingly negative impact on all three mistakes. Larger households with higher education make smaller mistakes, while entrepreneurs are more prone to all mistakes. Other variables, such as disposable income and real estate wealth, have a less stable effect, but this appears to result from the collinearity of the characteristics $x_{h, t}$. In the Appendix, we compute the simple correlation between these regressors and investment mistakes, and find that income and real estate wealth are negatively correlated with all three mistakes.

Investment mistakes themselves are only weakly correlated across households. The correlation between underdiversification and risky share inertia is $15.5 \%$, the correlation between underdiversification and the disposition effect measure is $-10.7 \%$, and the correlation between risky share inertia and the disposition effect measure is $5.1 \%$. When we consider instead the fitted values of the mistakes from Table 1 , the correlations are substantially higher, respectively $76.8 \%$, 53.4\%, and $80.9 \%$. These findings suggest that a single combination of household characteristics can be used to explain suboptimal investment behavior.

\section{B. Index of Financial Sophistication}

We construct an index of financial sophistication by regressing the negative of the mistake vector on a single linear combination of household characteristics:

$$
\begin{aligned}
-y_{h, t, 1} & =\left(\beta^{\prime} x_{h, t}\right)+\varepsilon_{h, t, 1}, \\
-y_{h, t, 2} & =\gamma_{2}\left(\beta^{\prime} x_{h, t}\right)+\varepsilon_{h, t, 2}, \\
-y_{h, t, 3} & =\gamma_{3}\left(\beta^{\prime} x_{h, t}\right)+\varepsilon_{h, t, 3} .
\end{aligned}
$$

We interpret $\left(\beta^{\prime} x_{h, t}\right)$ as an index of financial sophistication. Note that we have multiplied the mistake vector by -1 on the left-hand side, so that households with a higher index tend to make lower mistakes. The index is multiplied by proportionality constants $\gamma_{2}$ and $\gamma_{3}$ in the last two equations. The proportionality constant is normalized to unity in the first equation.

In Table 2, panel A, we report the results of the nonlinear least squares estimation of $\beta$ in (1). Households with high financial wealth, education and family size achieve a high index of sophistication. In Table 2, panel B, we also report the proportionality coefficients $\gamma_{2}$ and $\gamma_{3}$. They are both positive, which confirms that the index is associated with a lower level of all three mistakes. We observe that the proportionality restriction causes only a slight loss in explanatory power for underdiversification and inertia, but a more serious loss for the disposition effect compared to the unrestricted regressions reported in Table 1.

The correlation between the sophistication index and the risky share is equal to 0.35 . This result confirms the finding in CCS (2007) that more sophisticated agents tend to invest more aggressively and make smaller mistakes.

\section{Robustness Checks}

In the online Appendix, we have verified the robustness of our results to alternative assumptions about the household sample and the measurement of financial mistakes. First, we obtain similar results in a smaller subsample containing stockholders with both gains and losses in their stock portfolios, as in Dhar and Zhu (2006).

Second, we have considered several alternative measure of inertia. Risky share changes yield broadly similar, if slightly weaker, results in levels than in logs. General equilibrium considerations imply that changes in the target risky share are potentially important (CCS 2009). We have considered several proxies for the target, and have found that our main results are remarkably robust to these alternative measures.

Third, in the computation of the disposition effect, we have classified winners and losers according to their absolute performance during the year, rather than their performance relative to the world index. Since absolute gains are relatively rare during the severe bear market of our sample period, we confine attention to stockholders with both absolute gains and losses in their stock portfolios, and obtain similar results. Our results are also robust to counting a gain as realized only if the household fully disposes of the corresponding stock during the year.

Finally, the household-level Sharpe ratios used in Tables 1 and 2 are computed on the highly disaggregated asset-level data provided by Statistics Sweden. 
In other countries, however, researchers often have access to more limited information on household finances, and must typically rely on statistics such as the number of stocks, the number of funds, and the share of funds in the risky portfolio. In the Appendix, we have investigated how these measures relate to the Sharpe ratio. The share of funds in the risky portfolio appears to be a reasonable diversification proxy, with a 0.49 cross-sectional correlation with the Sharpe ratio. Furthermore, when we use this proxy in the regression of financial mistakes on characteristics, we obtain results that are broadly consistent with the results obtained with the Sharpe ratio. ${ }^{1}$ This is encouraging since the share of funds in the risky portfolio is readily available in a variety of datasets.

\section{Summary and Conclusions}

In this paper, we have confirmed earlier evidence that richer, educated households of larger size are less prone to making financial mistakes than other households. These results have motivated the construction of a single index of financial sophistication that best explains a set of three investment mistakes. The index of financial sophistication increases strongly with financial wealth and household size, and to a lesser extent with education and proxies for financial experience, but is lower for self-employed and immigrant households.

It is of course difficult to unambiguously establish that any behavior is a mistake, especially when one considers the possibility of nonstandard preferences. Douglas Bernheim and Antonio Rangel (2007) do consider both possibilities and acknowledge that mistakes can indeed occur. Our empirical finding that poorer, less educated, immigrant households are more prone to joint deviations from rational benchmarks makes it more plausible that these deviations are indeed mistakes.

A more direct approach is to correlate investors' behavior with their cognitive ability and financial lit-

\footnotetext{
${ }^{1}$ Variables such as the number of stocks or the number of funds, however, are poor diversification proxies, as evidenced by their small or even slightly negative correlation with the risky portfolio's Sharpe ratio. We have also considered a more elaborate imputation method based on the household's number of stocks and funds, the share of funds in the risky portfolio, as well as the average return, standard deviation, and correlation of stocks and funds. This method performs well but is only a very modest improvement over the share of funds.
}

eracy (e.g. Maarten van Rooij, Annamaria Lusardi and Rob Alessie, 2007). We have not pursued this approach but believe that this is a promising direction for future research.

Another way to detect if an observed behavior is a mistake is to ask whether a household with a high propensity to make mistakes understands that it has such a propensity and alters its behavior as a result. We have reported a strong positive correlation between a household's sophistication index and its share of risky assets. This correlation is consistent with the intuition developed in CCS (2007) that a household is willing to take financial risk when it is confident in its understanding of asset markets and the basic precepts of investing. In a recent and related contribution, Luigi Guiso, Paola Sapienza and Luigi Zingales (2007) emphasize the role of trust as a key determinant of participation and the risky share. The detailed analysis of these closely related views of risk-taking is left open for further research.

\section{REFERENCES}

Agnew, Julie, Pierluigi Balduzzi, and Annika Sundén. 2003. "Portfolio choice and trading in a large 401(k) plan.” American Economic Review 93(1): 193-215.

Bernheim, B. Douglas, and Antonio Rangel. 2007. "Beyond revealed preference: Choice theoretic foundations for behavioral welfare economics." Forthcoming Quarterly Journal of Economics.

Bilias, Yannis, Dimitris Georgarakos, and Michael Haliassos. 2008. "Portfolio inertia and stock market fluctuations.” Goethe University Frankfurt Working Paper.

Blume, Marshall, and Irwin Friend. 1975. “The asset structure of individual portfolios and some implications for utility functions.” Journal of Finance 30: 585-603.

Calvet, Laurent E., John Y. Campbell, and Paolo Sodini. 2007. "Down or out: Assessing the welfare costs of household investment mistakes." Journal of Political Economy, 115: 707-747.

Calvet, Laurent E., John Y. Campbell, and Paolo Sodini. 2009. "Fight or flight? Portfolio rebalancing by individual investors.” Forthcoming Quarterly Journal of Economics.

Campbell, John Y. 2006. "Household finance." Journal of Finance 61: 1553-1604. 
Dhar, Ravi, and Ning Zhu. 2006. "Up close and personal: investor sophistication and the disposition effect.” Management Science 52: 726-740.

Goetzmann, William N., and Alok Kumar. 2008. "Equity portfolio diversification.” Review of Finance 12: 433-463.

Guiso, Luigi, Paola Sapienza, and Luigi Zingales. 2007. "Trusting the stock market.” Forthcoming Journal of Finance.

Odean, Terrance. 1998. "Are investors reluctant to realize their losses?” Journal of Finance 53: 17751798.

van Rooij, Maarten, Annamaria Lusardi, and Rob Alessie. 2007. "Financial literacy and stock market participation.” Dartmouth College and Netspar Working Paper.

Vissing-Jorgensen, Annette. 2002. “Towards an explanation of household portfolio choice heterogeneity: Nonfinancial income and participation cost structures.” NBER Working Paper 8884.

Vissing-Jorgensen, Annette. 2003. "Perspectives on behavioral finance: does "irrationality" disappear with wealth? Evidence from expectations and actions.” In Mark Gertler and Kenneth Rogoff eds. NBER Macroeconomics Annual 2003 (MIT Press, Cambridge, MA). 
TABle 1: Regression of Investment Mistakes on Household Characteristics

\begin{tabular}{|c|c|c|c|c|c|c|}
\hline & \multicolumn{2}{|c|}{ "Underdiversification } & \multicolumn{2}{|c|}{ Risky Share Inertia } & \multicolumn{2}{|c|}{ "Disposition Effect } \\
\hline & Estimate & t-stat & Estimate & t-stat & Estimate & t-stat \\
\hline \multicolumn{7}{|l|}{ Financial Characteristics } \\
\hline Disposable income & 0.841 & 14.50 & 2.329 & 13.00 & -0.626 & -4.27 \\
\hline Private pension premia/income & -0.541 & -9.45 & -0.387 & -2.18 & 0.076 & 0.52 \\
\hline Log financial wealth & -3.814 & -59.70 & -11.510 & -58.10 & -7.179 & -44.40 \\
\hline Log real estate wealth & -0.696 & -11.00 & 1.597 & 8.14 & 0.632 & 3.94 \\
\hline Log total liability & -0.156 & -2.17 & -1.205 & -5.42 & -1.196 & -6.59 \\
\hline Retirement dummy & -0.401 & -1.86 & -1.710 & -2.56 & 1.065 & 1.95 \\
\hline Unemployment dummy & 0.768 & 3.35 & -0.390 & -0.55 & 2.340 & 4.04 \\
\hline Entrepreneur dummy & 1.297 & 5.12 & 10.835 & 13.80 & 6.481 & 10.10 \\
\hline Student dummy & 1.067 & 2.32 & -4.288 & -3.01 & -1.919 & -1.65 \\
\hline \multicolumn{7}{|l|}{ Demographic Characteristics } \\
\hline Age & 0.037 & 5.95 & -0.070 & -3.61 & 0.016 & 1.04 \\
\hline Household size & -1.420 & -28.10 & -0.991 & -6.32 & 2.022 & 15.80 \\
\hline High school dummy & -0.654 & -4.02 & -1.166 & -2.31 & -2.705 & -6.58 \\
\hline Post-high school dummy & 0.246 & 1.85 & -0.089 & -0.22 & -3.834 & -11.40 \\
\hline $\begin{array}{l}\text { Dummy for unavailable education } \\
\text { data }\end{array}$ & 2.930 & 11.70 & 0.113 & 0.15 & -3.969 & -6.28 \\
\hline Immigration dummy & 3.447 & 19.00 & 4.289 & 7.62 & -5.216 & -11.40 \\
\hline Adjusted $R^{2}$ & $6.96 \%$ & & $4.27 \%$ & & $3.13 \%$ & \\
\hline Number of observations & 102,731 & & 102,731 & & 102,731 & \\
\hline
\end{tabular}


TABLE 2: RESTRICTED REGRESSION

\section{A. Sophistication Index}

\begin{tabular}{lrrr}
\hline \hline & Estimate & t-stat & Correlation \\
\hline Financial Characteristics & & & \\
Disposable income & -0.673 & -15.80 & 0.137 \\
Private pension premia/income & 0.322 & 7.70 & 0.184 \\
Log financial wealth & 4.335 & 72.40 & 0.923 \\
Log real estate wealth & 0.073 & 1.58 & 0.304 \\
Log total liability & 0.379 & 7.24 & -0.009 \\
Retirement dummy & 0.313 & 1.99 & 0.010 \\
Unemployment dummy & -0.614 & -3.67 & -0.114 \\
Entrepreneur dummy & -2.865 & -15.40 & -0.095 \\
Student dummy & 0.243 & 0.72 & -0.062 \\
Demographic Characteristics & & & \\
Age & -0.012 & -2.58 & 0.071 \\
Household size & 0.632 & 17.00 & 0.277 \\
High school dummy & 0.805 & 6.78 & 0.164 \\
Post-high school dummy & 0.327 & 3.36 & 0.212 \\
Dummy for unavailable education data & -1.070 & -5.86 & -0.070 \\
Immigration dummy & -1.751 & -13.10 & -0.136 \\
\hline Number of observations & 102,731 & & \\
\hline
\end{tabular}

B. Proportionality Coefficients and Adjusted $R^{2}$

\begin{tabular}{lrrr}
\hline \hline & \multicolumn{2}{c}{ Proportionality Coefficient } & Adjusted $R^{2}$ \\
\cline { 2 - 3 } & Estimate & t-stat & \\
\hline Underdiversification & - & - & $6.02 \%$ \\
Risky share inertia & 2.414 & 49.80 & $3.76 \%$ \\
Disposition effect & 1.397 & 39.20 & $1.91 \%$ \\
\hline
\end{tabular}

Notes: This table reports the pooled restricted regressions of the negative of investment mistakes on household characteristics. In Panel A, we compute the coefficients of the sophistication index, their $t$-statistics, as well as the correlation of the index with each characteristic. In Panel B, we report the proportionality coefficient of risky share inertia and the disposition effect measure, and the adjusted $R^{2}$ of all three mistakes. The proportionality coefficient of underdiversification is by definition equal to unity and is not reported. The estimation is based on participants at $t$ and $t+1$ with direct stockholdings at $t$ for which the immigration dummy is available. Mistakes are expressed in percentage points. All mistakes and characteristics are demeaned year by year, and continuous characteristics are also standardized year by year. 


\title{
Appendix to "Measuring the Financial Sophistication of Households"*
}

\author{
Laurent E. Calvet, John Y. Campbell and Paolo Sodini
}

First version: January 2009

\section{Data Description and Definitions}

Swedish households pay taxes on both income and wealth. For this reason, the national Statistics Central Bureau (SCB), also known as Statistics Sweden, has a parliamentary mandate to collect highly detailed information on the finances of every household in the country. We compiled the data supplied by SCB into a panel covering four years (1999-2002) and all Swedish residents (about 4.8 million households). The information available on each resident can be grouped into three main categories: demographic characteristics, income, and disaggregated wealth.

Demographic information includes age, gender, marital status, nationality, birthplace, education, and place of residence. The household head is defined as the individual with the highest income. The education variable includes high school and post-high school dummies for the household head.

Income is reported by individual source. For capital income, the database reports the income (interest, dividends) that has been earned on each bank account or each security. For labor income, the database reports gross labor income and business sector.

The panel's distinguishing feature is that it contains highly disaggregated wealth information. We observe the worldwide assets owned by each resident on December

${ }^{*}$ Calvet: Department of Finance, HEC Paris, 1 avenue de la Libération, 78351 Jouy-en-Josas, France; and NBER, calvet@hec.fr. Campbell: Department of Economics, Littauer Center, Harvard University, Cambridge, MA 02138, USA, and NBER, john_campbell@harvard.edu. Sodini: Department of Finance, Stockholm School of Economics, Sveavägen 65, Box 6501, SE-113 83 Stockholm, Sweden, Paolo.Sodini@hhs.se. 
31 of each year, including bank accounts, mutual funds and stocks. The information is provided for each individual account or each security referenced by its International Security Identification Number (ISIN). The database also records contributions made during the year to private pension savings, as well as debt outstanding at year end and interest paid during the year.

Following Calvet, Campbell, and Sodini (henceforth "CCS", 2007), we measure a household's total financial wealth as the sum of its holdings in these asset classes, excluding from consideration illiquid assets such as real estate or consumer durables, defined contribution retirement accounts, capital insurance products that combine return guarantees with risky asset holdings, and directly held bonds. Also, our measure of wealth is gross wealth and does not subtract mortgage or other household debt. CCS (2007) summarize the relative magnitudes of all these components of Swedish household balance sheets.

The results presented in this paper are based on households that exist throughout the 1999-2002 period. We impose no constraint on the participation status of these households, but require that they satisfy the following financial requirements at the end of each year. First, disposable income must be strictly positive and the three-year rolling average must be at least 1,000 Swedish kronor (\$113). Second, financial wealth must be no smaller than 3,000 kronor (\$339). For computational convenience, we have selected a random panel of 100,000 households from the filtered population. Unless stated otherwise, all the results in the paper and appendix are based on this fixed subsample.

\section{Additional Results on the Regressions Reported in the Main Text}

We begin by reporting additional results on the regressions presented in Tables 1 and 2 of the main text. In Table A1, we report the cross-sectional correlation of investment mistakes in the population of households considered in Tables 1 and 2. In the top left corner, we consider the correlation of observed mistakes. We find that risky share inertia has a slight positive correlation with underdiversification and the disposition effect, while the correlation between underdiversification and the disposition effect is slightly negative. In the bottom right corner, we report the correlation of fitted mistakes, which are computed using the unrestricted regression coefficients reported in Table 1 of the main text. All three correlations are strongly positive, ranging between $53.4 \%$ and $80.9 \%$. This suggests that it is possible to construct a single index of financial sophistication.

In Table A2, we report the simple correlation between characteristics and fitted mistakes. The fitted values are again computed using the unrestricted regression coefficients reported in Table 1. Disposable income, private pension premia, real estate wealth, the 
post-high school dummy, and most strikingly financial wealth are all negatively correlated with the three mistakes. We conversely obtain positive correlations between mistakes and the retirement or entrepreneurs dummies. Thus, the collinearity of regressors seems to explain apparent instability in the signs of some coefficients reported in Table 1.

In Table A3, we report the restricted regression coefficients of investment mistakes on household characteristics. The results are derived from Table 2 in the main text, and have the advantage of being directly comparable to Table 1 . Log financial wealth has approximately the same coefficients as the ones obtained in the unrestricted regression, while larger differences are apparent for other regressors.

\section{Robustness Checks}

\subsection{Disposition Effect}

Stockholders with Both Gains and Losses. In Tables A4-A6, we reestimate the sophistication regressions on the set of participating stockholders with both gains and losses in their stock portfolios. Dhar and Zhu (2006) impose a similar requirement on the set of households they consider in their analysis. As in the main text, we classify a stock as a winner if its performance during the year is higher than the unhedged version of the MSCI world index. We verify in Table A4 that financial wealth, and to a lesser extent household size and education, have a negative impact on all three mistakes, and we observe in Table A5 that the fitted values of investments mistakes have high positive correlations. As is apparent in Table A6, the reduction of the $R^{2}$ coefficient in the restricted regression is modest for underdiversification and inertia, but more pronounced for the disposition effect. The index of financial sophistication increases with financial wealth, household size and education, but tends to be lower for immigrants, entrepreneurs and the unemployed. Thus, the results reported in the main text are robust to the choice of this alternative subsample.

Losers and Winners Defined by Absolute Performance During the Year. In Tables A7-A9, we classify a stock as a winner if it has a positive return during the year, and as a loser otherwise. We reestimate the sophistication regressions and mistake correlations on the set of participating stockholders with both gains and losses in their stock portfolios. Tables A7-A9 show that the results of the main text are robust to the choice of alternative stock classification and household subsample.

Disposition Effect Computed Using Full Sales Only. In Tables A10-A12, we investigate the robustness of our results when the measure of the disposition effect only takes full sales into account. We focus on participating stockholders who sell at least 
one stock (either partially or fully) and experience both gains and losses in their stock portfolios during the year. Gains and losses are calculated with respect to the unhedged world index. We verify in Tables A10-A12 that the results reported in the main text are robust to considering only full sales in the disposition effect measure.

\subsection{Risky Share Inertia}

We now consider two alternative measure of risky share inertia.

Risky Share Changes in Levels. In Tables A13-A15, we proxy inertia by the absolute value of risky share changes in levels, $\left|w_{h, t+1}-w_{h, t}\right|$. We obtain broadly similar, if slightly weaker, results than in logs.

Adjustment Model. In CCS (2009), we have introduced an adjustment model of the risky share. For every household $h$, we write the period- $t+1$ risky share, $w_{h, t+1}$, as the weighted average of the households's passive share, $w_{h, t+1}^{p}$, and target share, $w_{h, t+1}^{d}$ :

$$
\ln \left(w_{h, t+1}\right)=\left(1-\phi_{h}\right) \ln \left(w_{h, t+1}^{p}\right)+\phi_{h} \ln \left(w_{h, t+1}^{d}\right),
$$

The passive share $w_{h, t+1}^{p}$ is the proportion of risky assets in the complete portfolio at the end of year $t+1$ if the household passively holds its year- $t$ portfolio for an entire year. The passive share can be readily computed for every household. By contrast, the target $w_{h, t+1}^{d}$ is unobserved and is estimated, along with the adjustment coefficient $\phi_{h}$, by instrumental variable regression in CCS (2009).

We now use the adjustment model to define a proxy for inertia that can be readily computed for every household. The adjustment equation implies that the inertia measure $1-\phi_{h}$ satisfies

$$
1-\phi_{h}=\frac{\ln \left(w_{h, t+1}\right)-\ln \left(w_{h, t+1}^{d}\right)}{\ln \left(w_{h, t+1}^{p}\right)-\ln \left(w_{h, t+1}^{d}\right)} .
$$

The numerator can be decomposed as follows:

$$
\ln \left(w_{h, t+1}\right)-\ln \left(w_{h, t+1}^{d}\right)=\Delta \ln \left(w_{h, t+1}\right)-\Delta \ln \left(w_{h, t+1}^{d}\right)+\ln \left(w_{h, t}\right)-\ln \left(w_{h, t}^{d}\right) .
$$

We classify households into bins of the initial risky share $w_{h, t}$, and proxy the target change $\Delta \ln \left(w_{h, t+1}^{d}\right)$ by the equal-weighted average of the risky share change among households in the same bin, $\Delta T_{h, t+1}$. If we also assume that $w_{h, t}=w_{h, t}^{d}$, then

$$
\ln \left(w_{h, t+1}\right)-\ln \left(w_{h, t+1}^{d}\right) \approx \Delta \ln \left(w_{h, t+1}\right)-\Delta T_{h, t+1} .
$$


Let $p_{h, t+1}=\ln \left(w_{h, t+1}\right)-\ln \left(w_{h, t+1}^{d}\right)$ denote the passive change. The denominator of (3.1) can similarly be rewritten as:

$$
\begin{aligned}
\ln \left(w_{h, t+1}^{p}\right)-\ln \left(w_{h, t+1}^{d}\right) & =p_{h, t+1}-\Delta \ln \left(w_{h, t+1}^{d}\right)+\ln \left(w_{h, t}\right)-\ln \left(w_{h, t}^{d}\right) \\
& \approx p_{h, t+1}-\Delta T_{h, t+1} .
\end{aligned}
$$

Given these approximations, we define the following proxy for the inertia coefficient:

$$
y_{h, t, 2}=\left|\frac{\Delta \ln \left(w_{h, t+1}\right)-\Delta T_{h, t+1}}{p_{h, t+1}-\Delta T_{h, t+1}}\right| .
$$

Since changes in the target are poorly estimated, we take absolute values and winsorize the ratio to reduce noise. ${ }^{1}$

In Tables A16-A18, we reestimate the sophistication regressions and mistake correlations when the inertia coefficient $y_{h, t, 2}$ is winsorized at the 95 th percentile. The results are broadly consistent with the findings of the main text. Significance levels, correlations, and $R^{2}$ coefficients are lower than in Tables 1 and 2 because of the noisiness of this alternative measure.

In Tables A19-A21, we confirm this interpretation by winsorizing the inertia coefficient at the 90th percentile. The reduction in noise leads to higher significance levels and $R^{2}$, as one would expect. The correlation coefficients are slightly lower, however, presumably because winsorization reduces the covariance between the inertia measure and other mistakes. Overall, this analysis confirms that the results in the main text are robust to the choice of alternative measures of inertia based on the adjustment model.

Market Measure of Inertia. Consider a general equilibrium economy in which the representative agent holds the market portfolio. At the end of the following year, her new target risky share must coincide with her passive risky share:

$$
\omega^{p}\left(w_{h, t} ; r_{m, t+1}\right)=\frac{w_{h, t}\left(1+r_{m, t+1}\right)}{1+r_{f, t}+w_{h, t}\left(r_{m, t+1}-r_{f, t}\right)} .
$$

These considerations lead us to proxy household inertia by the market measure:

$$
y_{h, t, 2}=\left|\ln \left(w_{h, t+1}\right)-\ln \omega^{p}\left(w_{h, t} ; r_{m, t+1}\right)\right|,
$$

\footnotetext{
${ }^{1}$ The following example illustrates why the measure of inertia is quite noisy. Consider a closed economy in which the representative agent passively holds the market portfolio. The numerator and denominator of$$
\frac{\Delta \ln \left(w_{h, t+1}\right)-\Delta T_{h, t+1}}{p_{h, t+1}-\Delta T_{h, t+1}}
$$

are then both equal to zero. The sign and magnitude of the ratio are thus unstable for households that are close to the mean. Since we have shown in CCS (2009) that the inertia coefficient is contained between 0 and 1 for almost all households, we reduce noise by taking absolute values and winsorizing the upper tail of $y_{h, t, 2}$.
} 
where $r_{m, t+1}$ is the return on the unhedged world index. $y_{h, t, 2}$ is the distance between the actual risky share, $w_{h, t+1}$, and a proxy for the target, $\omega^{p}\left(w_{h, t} ; r_{m, t+1}\right)$.

In Tables A22-A24, we reestimate the sophistication regressions when inertia is proxied by the market measure. The results are consistent, if slightly weaker, than the estimates reported in the main text.

\section{Measuring Diversification on Less Detailed Datasets}

We have hitherto computed household-level Sharpe ratios from the highly disaggregated asset-level data provided by Statistics Sweden. In other countries, however, researchers often have access to more limited information on household finances, and must rely on statistics such as the number of stocks, the number of funds, and the share of funds in the risky portfolio, as diversification proxies. In Table A25, we report the cross-sectional correlation between these proxies and the actual Sharpe ratio in our dataset. Specifically, for every household $h$, we consider the number of stocks $n_{h}$ in the risky portfolio, the number of risky funds $m_{h}$, the total number of risky assets $n_{h}+m_{h}$, the share of risky assets in funds $F_{h}$, and the weighted number of risky assets: $\left(1-F_{h}\right) n_{h}+F_{h} m_{h}$. We also consider a more elaborate imputation method of the Sharpe ratio, which is based on the household's number of stocks and funds, the share of funds in the risky portfolio, as well as the average return, standard deviation and correlation of stocks and funds. The exact definition of the imputed Sharpe ratio is provided at the end of the section.

The share of funds in the risky portfolio is a reasonable diversification proxy, with a 0.49 cross-sectional correlation with the Sharpe ratio. The imputed Sharpe ratio performs well but provides only a tiny improvement in the correlation compared to the share of funds. Variables such as the number of stocks or the number of risky assets, however, are poor diversification proxies, as evidenced by their small or slightly negative correlation with the risky portfolio's Sharpe ratio. In Tables A26-A28, we reestimate the sophistication regressions when the share of funds in the risky portfolio is used as a diversification proxy. The results are qualitatively similar to the ones obtained in the main text.

In Tables A29-A31, we reestimate the sophistication regressions based on the imputed Sharpe ratio. The results are consistent with the ones obtained with the fund share and the actual Sharpe ratio. Predicted correlations and $R^{2}$ coefficients, however, are substantially larger than with the Sharpe ratio and the fund share, which suggests that these estimates should be interpreted with caution when using the imputed the Sharpe ratio in other datasets.

Overall, the share of funds in the risky portfolio appears to be a reasonable proxy for risky portfolio diversification. This is encouraging news for household finance researchers since these measures are readily available in many countries. 


\subsection{Imputed Sharpe Ratio}

As in CCS (2007), we assume that assets are priced on world markets in dollars according to a global version of the CAPM. From the perspective of a Swedish investor, the pricing model induces a domestic CAPM in which the currency-hedged world index is mean-variance efficient. Because currency-hedging is typically unavailable to most retail investors, except perhaps the richest, we view the unhedged version of the index as more attainable. The computation of the imputed Sharpe ratio then proceeds as follows.

- The CAPM implies that the excess return on the equal-weighted Swedish index has mean $\mu_{S I}=7.35 \%$ and volatility $\sigma_{S I}=31.2 \%$.

- The excess return on a stock held by a Swedish household has mean $\mu_{D}=\mu_{S I}$, average volatility $\sigma_{D}=71.61 \%$, and average pairwise correlation $\rho=8 \%$. The computation of $\sigma_{D}$ and $\rho$ is based on the variance-covariance matrix of excess returns implied by the CAPM.

- The unhedged world index has expected excess return $\mu_{m}=5.52 \%$, volatility $\sigma_{m}=15.98 \%$, and Sharpe ratio $S_{m}=34.56 \%$ (from the CAPM).

- The average correlation between an individual stock and the unhedged index is $\rho^{*}=28.32 \%$.

We now consider the household's stock and fund portfolios. The household's stock portfolio yields the excess return:

$$
r_{h, D, t}=\frac{1}{n_{h}} \sum_{i=1}^{n_{h}} r_{i, t}
$$

which has mean $\mu_{D}$ and variance $\sigma_{h, D}^{2}=\sigma_{D}^{2}\left[1+\left(n_{h}-1\right) \rho\right] / n_{h}$. We assume that fund holdings are invested in the unhedged version of the world index.

Under these assumptions, the excess return on the risky portfolio,

$$
r_{h, t}=D_{h, t} r_{h, D, t}+\left(1-D_{h, t}\right) r_{m, t},
$$

has mean $E\left(r_{h, t}\right)=D_{h, t} \mu_{D}+\left(1-D_{h, t}\right) \mu_{m}$ and variance $\sigma_{h, t}^{2}=D_{h, t}^{2} \sigma_{h, D}^{2}+\left(1-D_{h, t}\right)^{2} \sigma_{m}^{2}+$ $2 D_{h, t}\left(1-D_{h, t}\right) \rho^{*} \sigma_{m} \sigma_{D}$. We therefore proxy the household's Sharpe ratio by:

$$
I S_{h, t}=\frac{D_{h, t} \mu_{D}+\left(1-D_{h, t}\right) \mu_{m}}{\left[D_{h, t}^{2} \sigma_{h, D}^{2}+\left(1-D_{h, t}\right)^{2} \sigma_{m}^{2}+2 D_{h, t}\left(1-D_{h, t}\right) \rho^{*} \sigma_{m} \sigma_{D}\right]^{1 / 2}} .
$$

The corresponding underdiversification measure is $1-I S_{h, t} / S_{m}$. 


\section{References}

[1] Calvet, Laurent E., John Y. Campbell and Paolo Sodini, 2007, Down or out: Assessing the welfare costs of household investment mistakes, Journal of Political Economy $115,707-747$.

[2] Calvet, Laurent E., John Y. Campbell and Paolo Sodini, 2009, Fight or flight? Portfolio rebalancing by individual investors, forthcoming Quarterly Journal of Economics.

[3] Dhar, Ravi, and Ning Zhu, 2006, Up close and personal: investor sophistication and the disposition effect, Management Science 52, 726-740.

[4] Odean, Terrance, 1998, Are investors reluctant to realize their losses?, Journal of Finance 53, 1775-1798. 


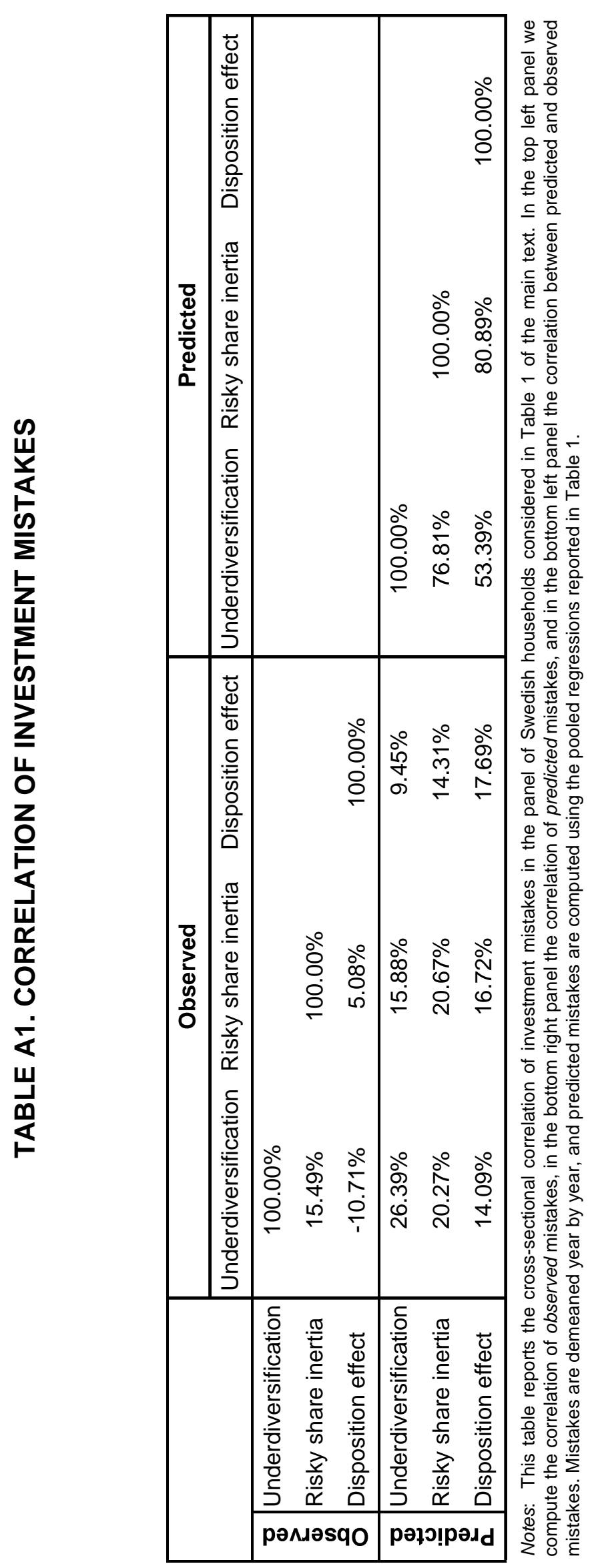




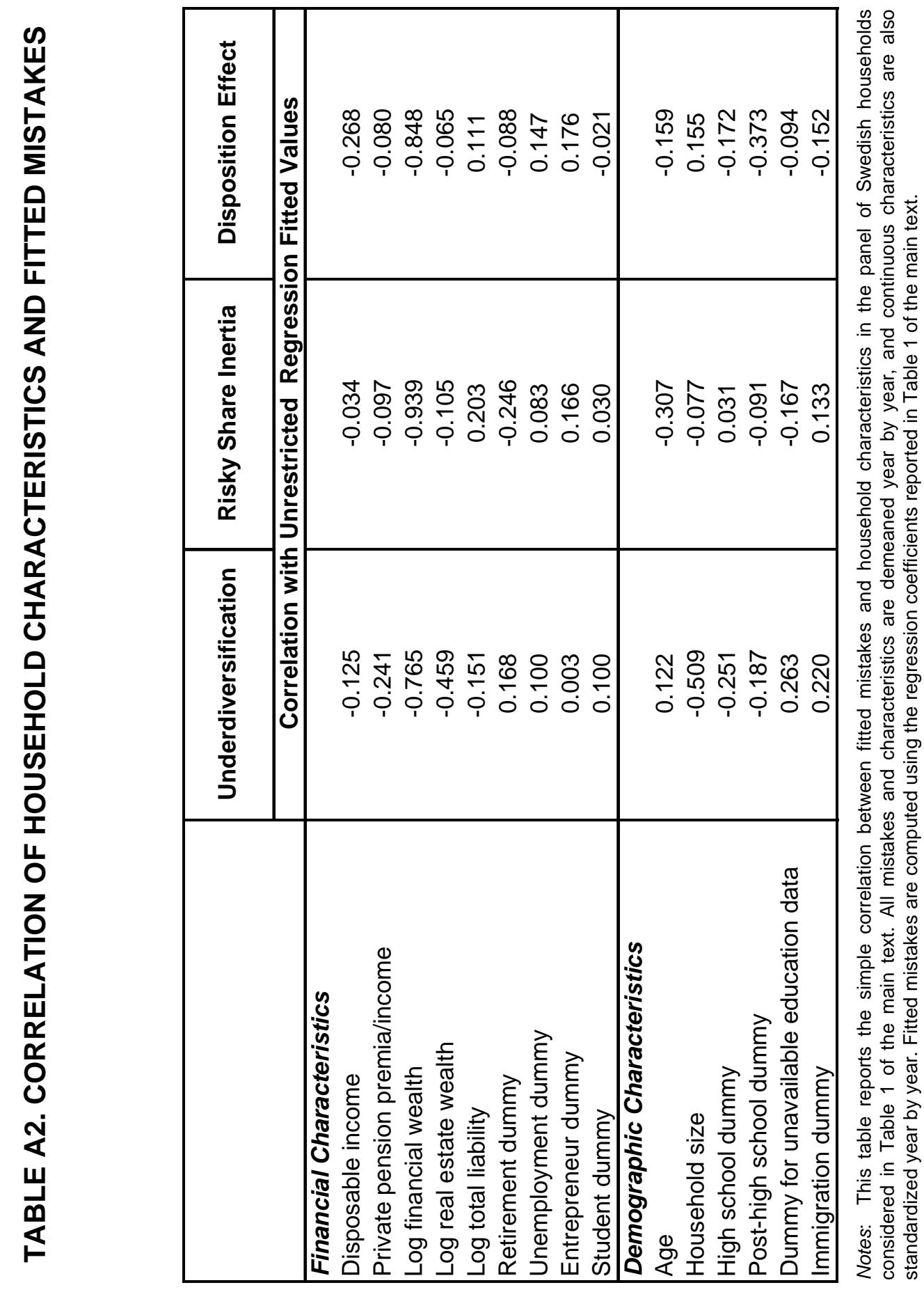




\begin{tabular}{|c|c|c|c|c|c|}
\hline 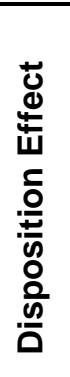 & 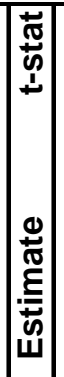 & 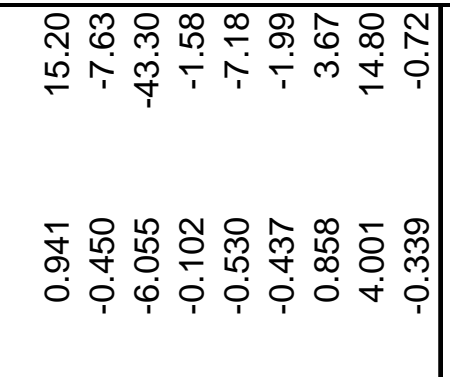 & 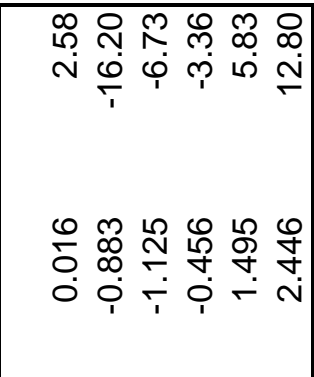 & 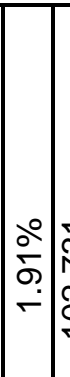 & 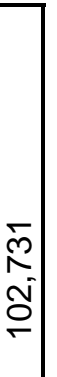 \\
\hline 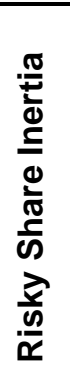 & 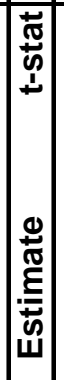 & 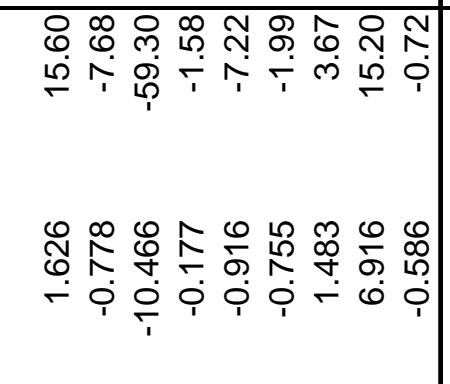 & 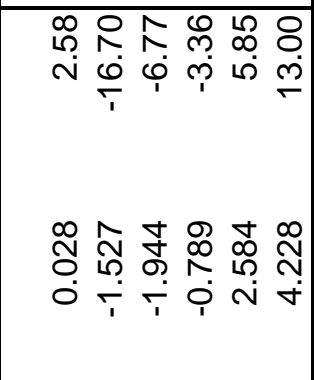 & $\mid \begin{array}{c}0 \\
b \\
c \\
m \\
m\end{array}$ & 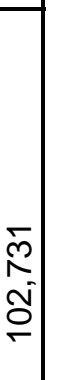 \\
\hline 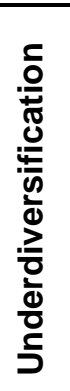 & 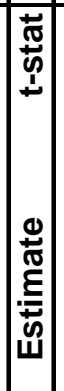 & 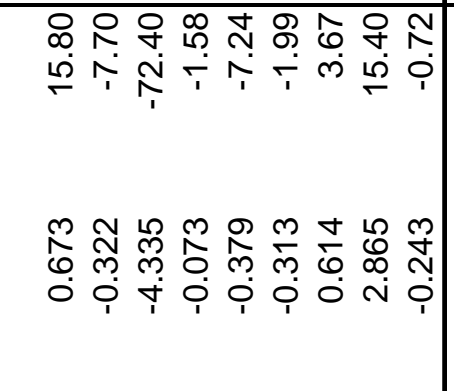 & 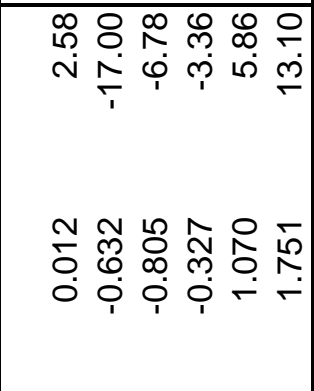 & $\mid$ & 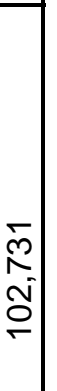 \\
\hline & & 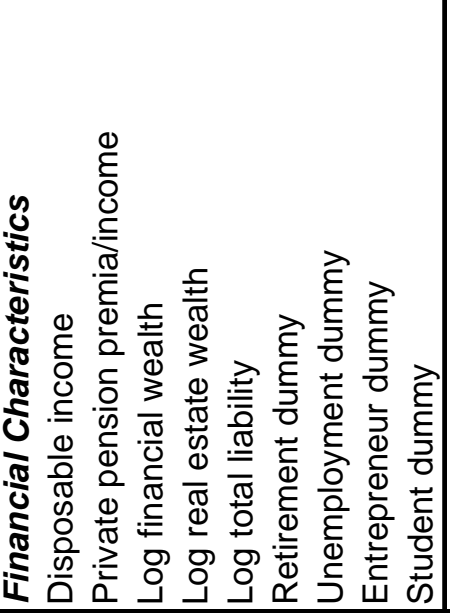 & 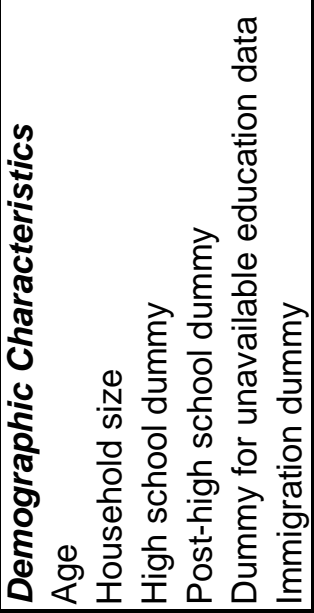 & $\mid$ & 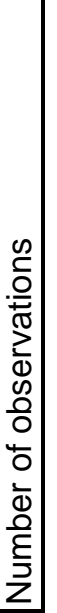 \\
\hline
\end{tabular}




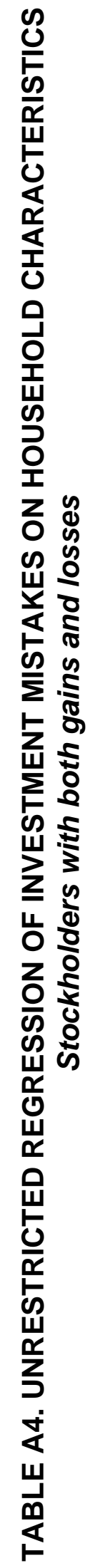

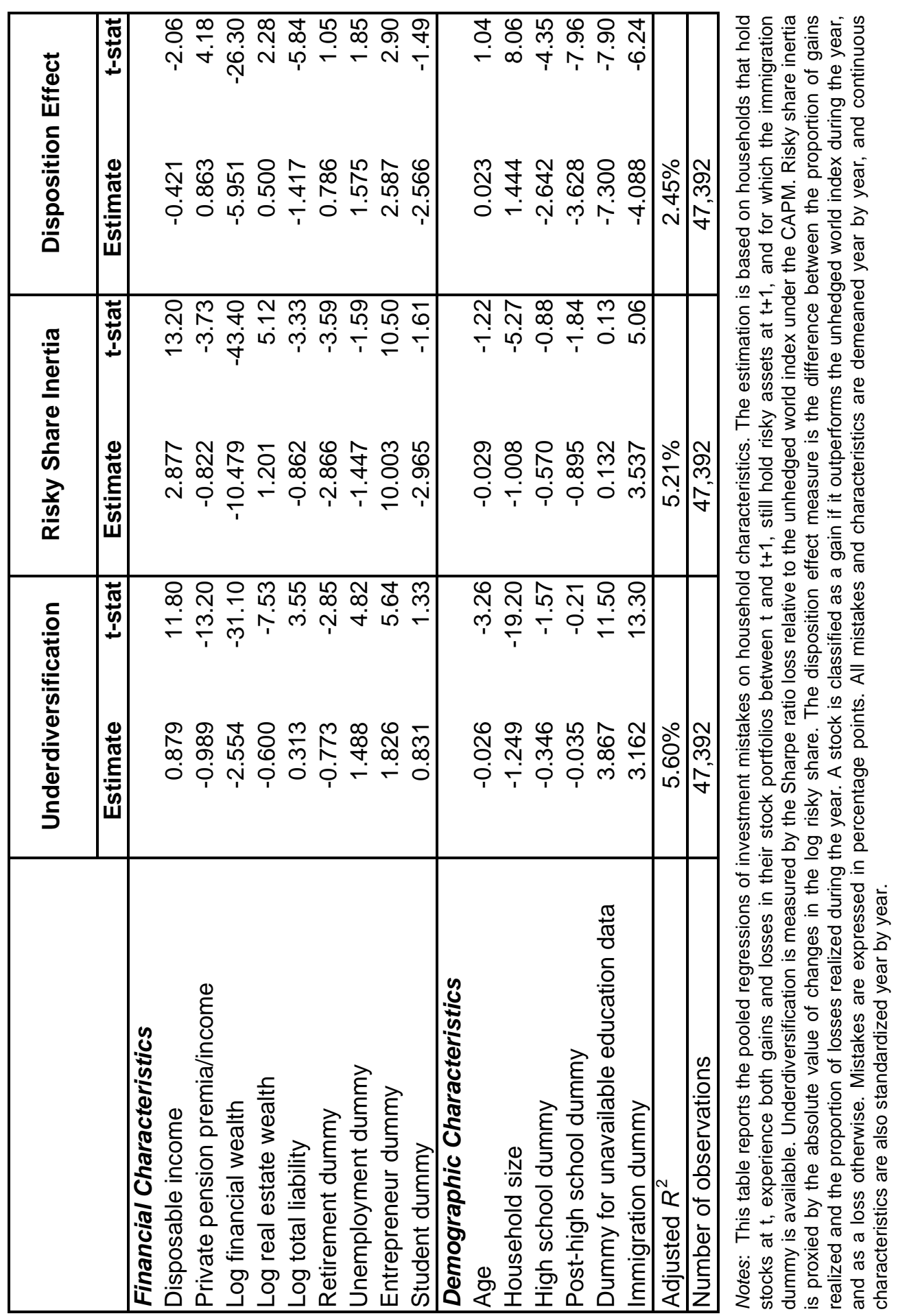




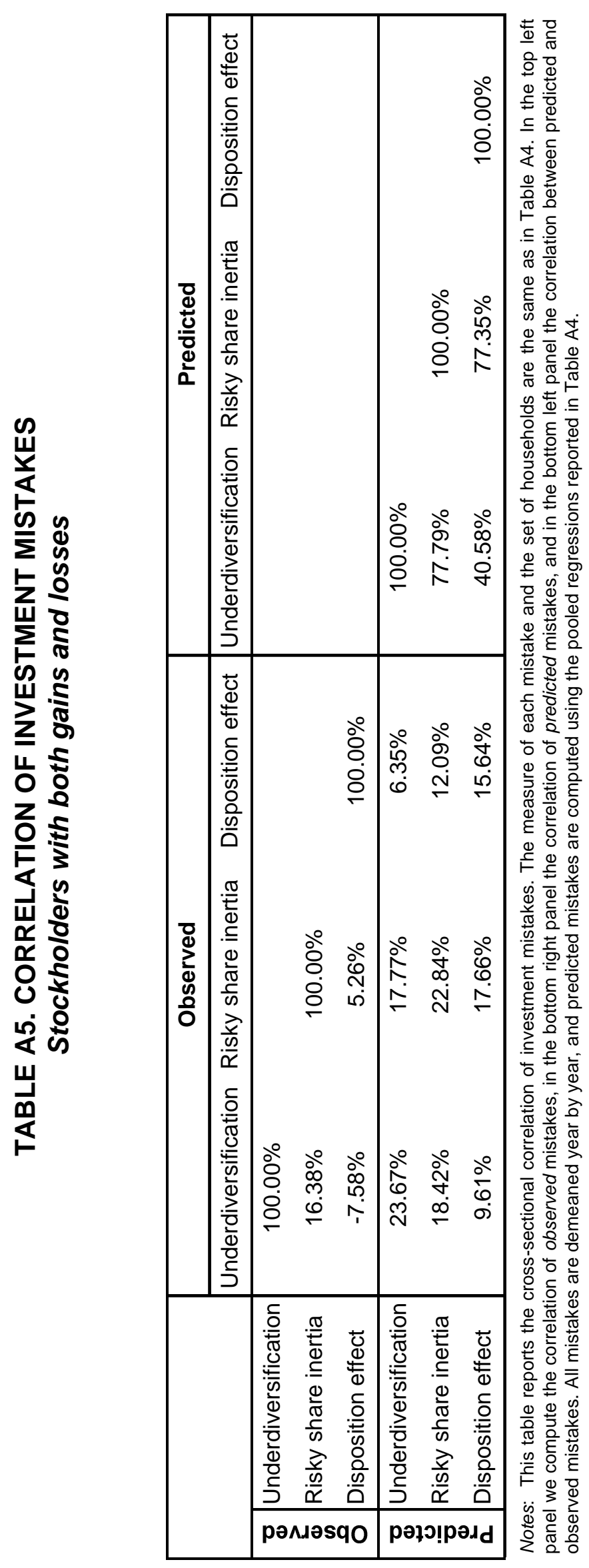




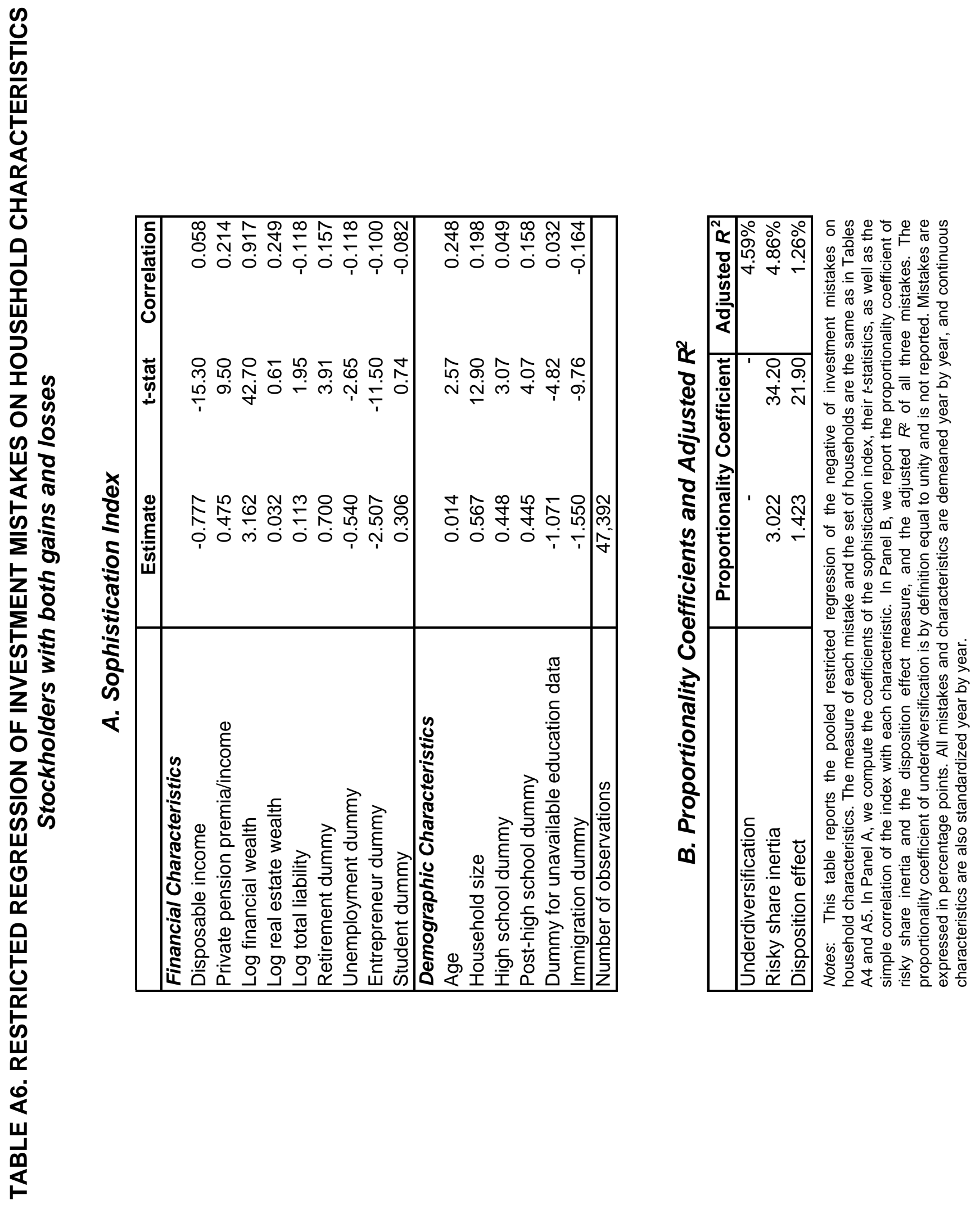




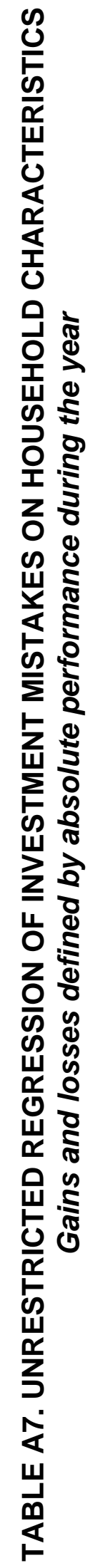

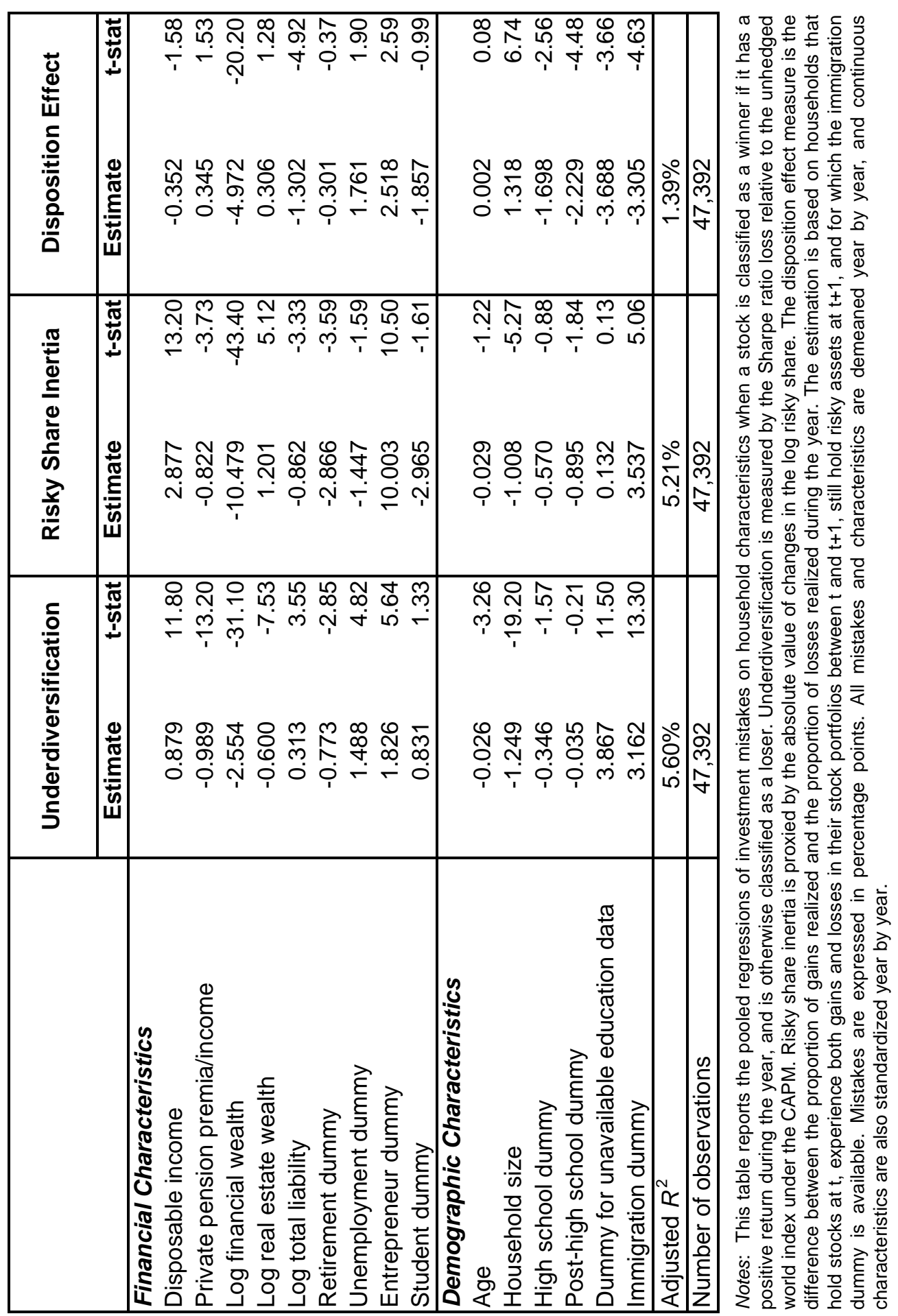




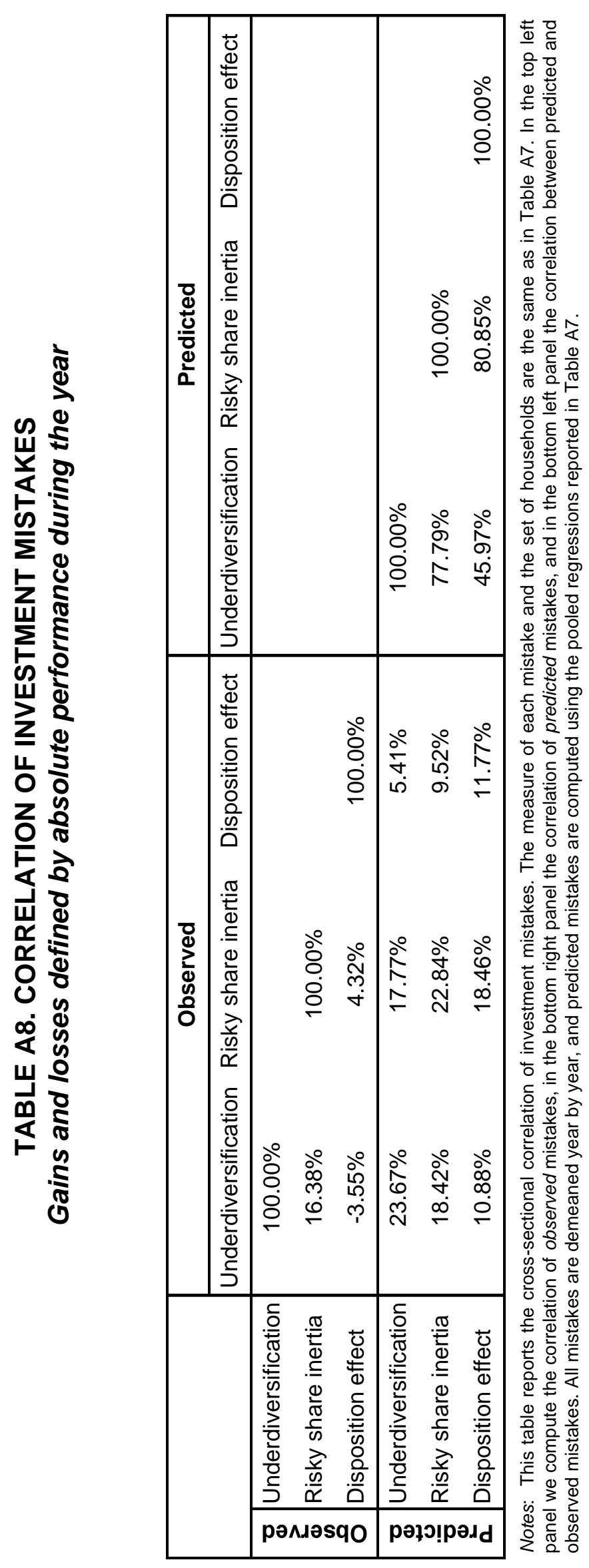




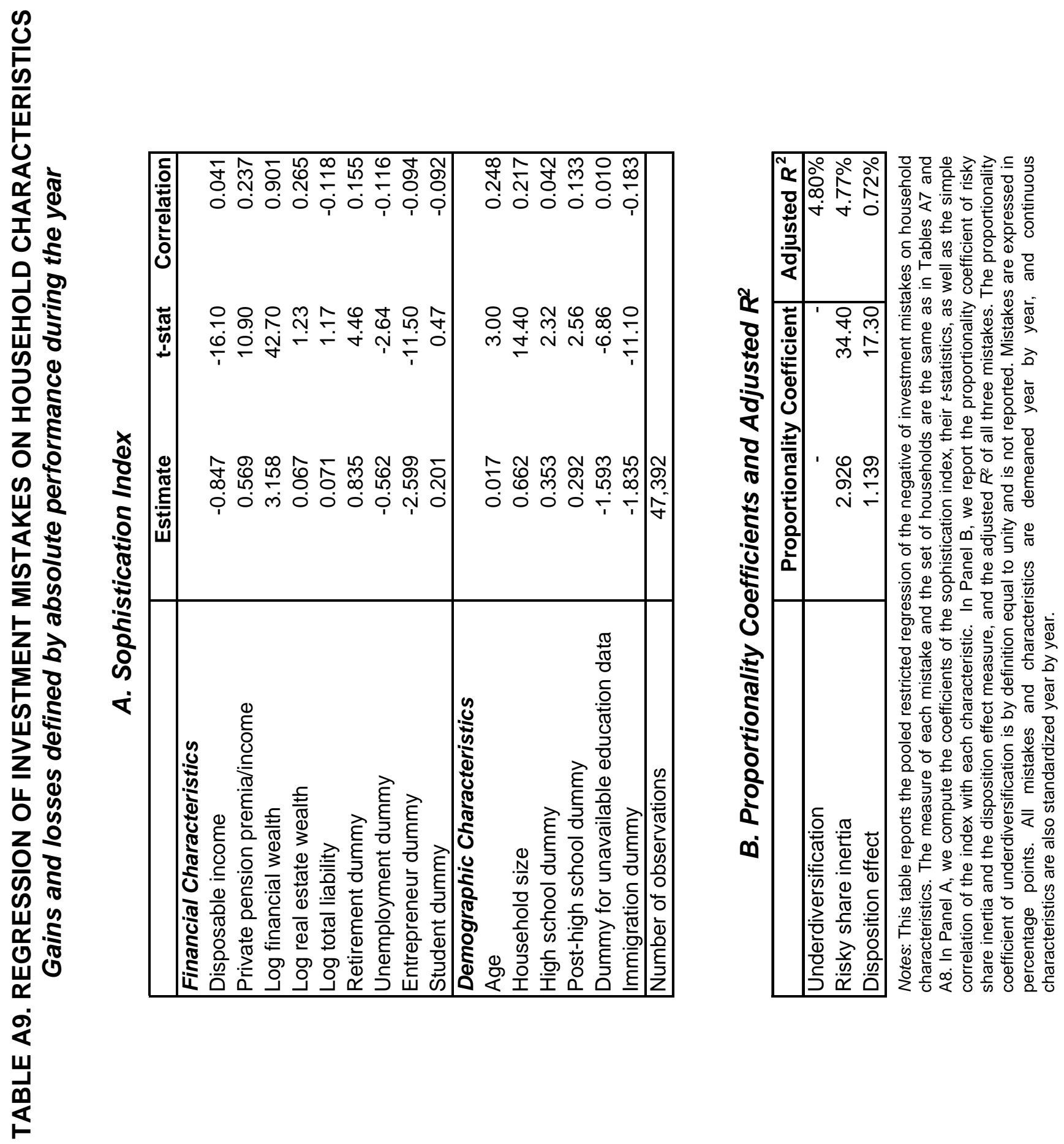



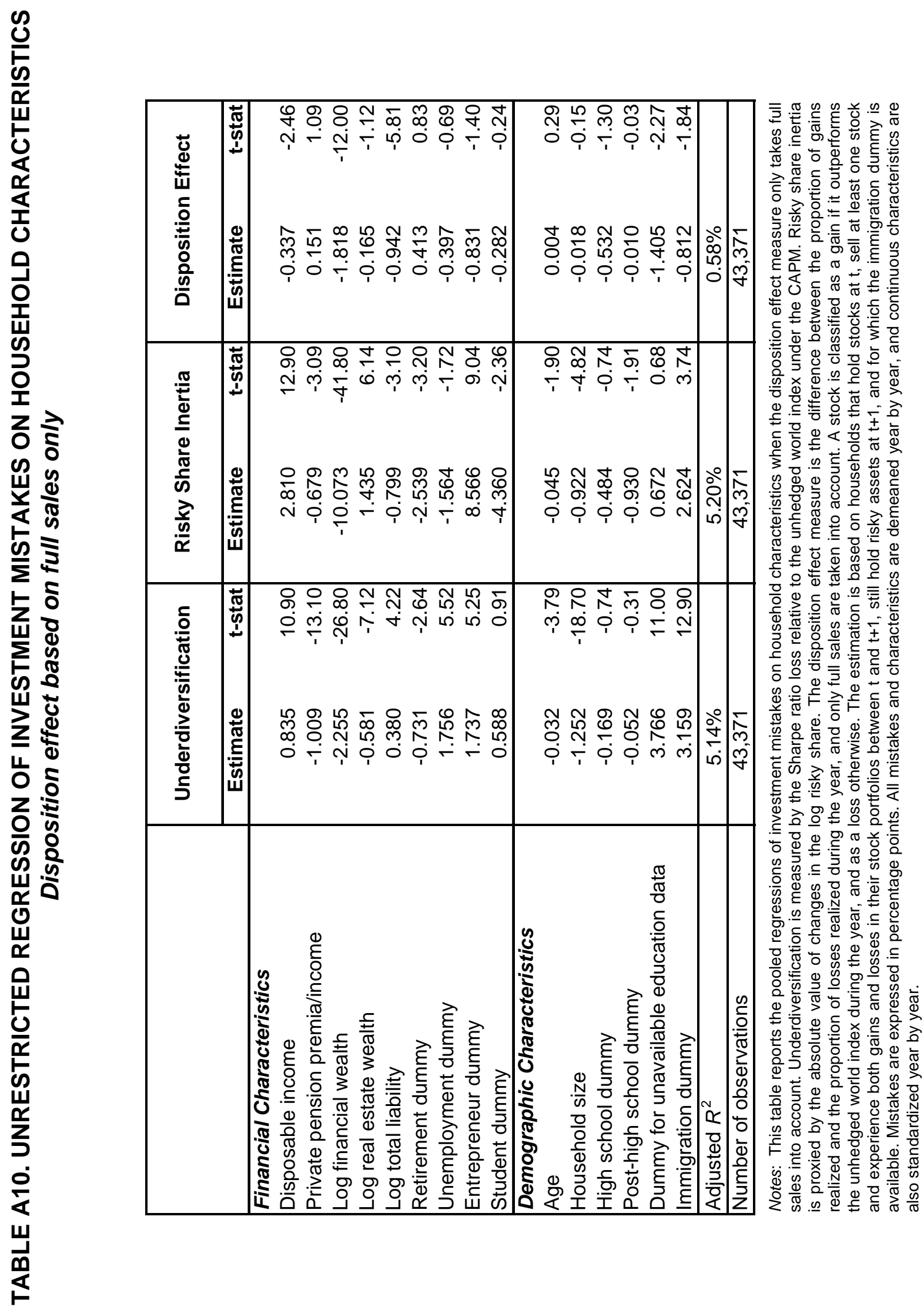


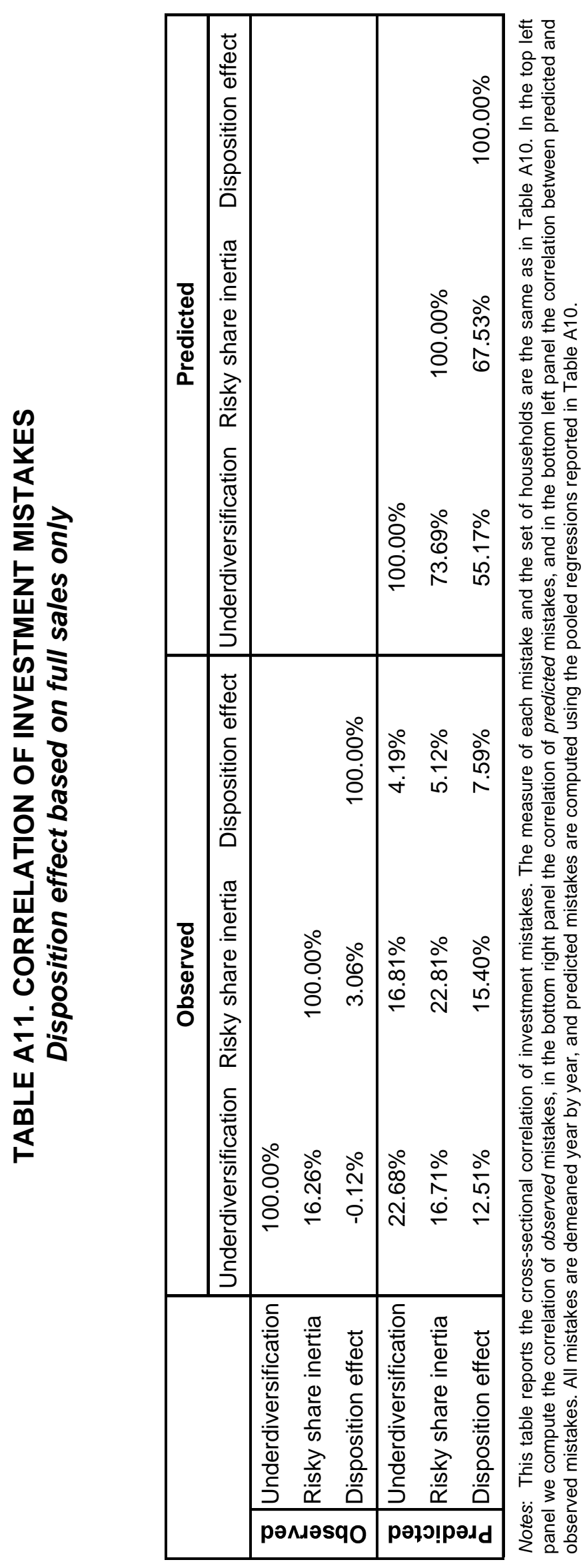




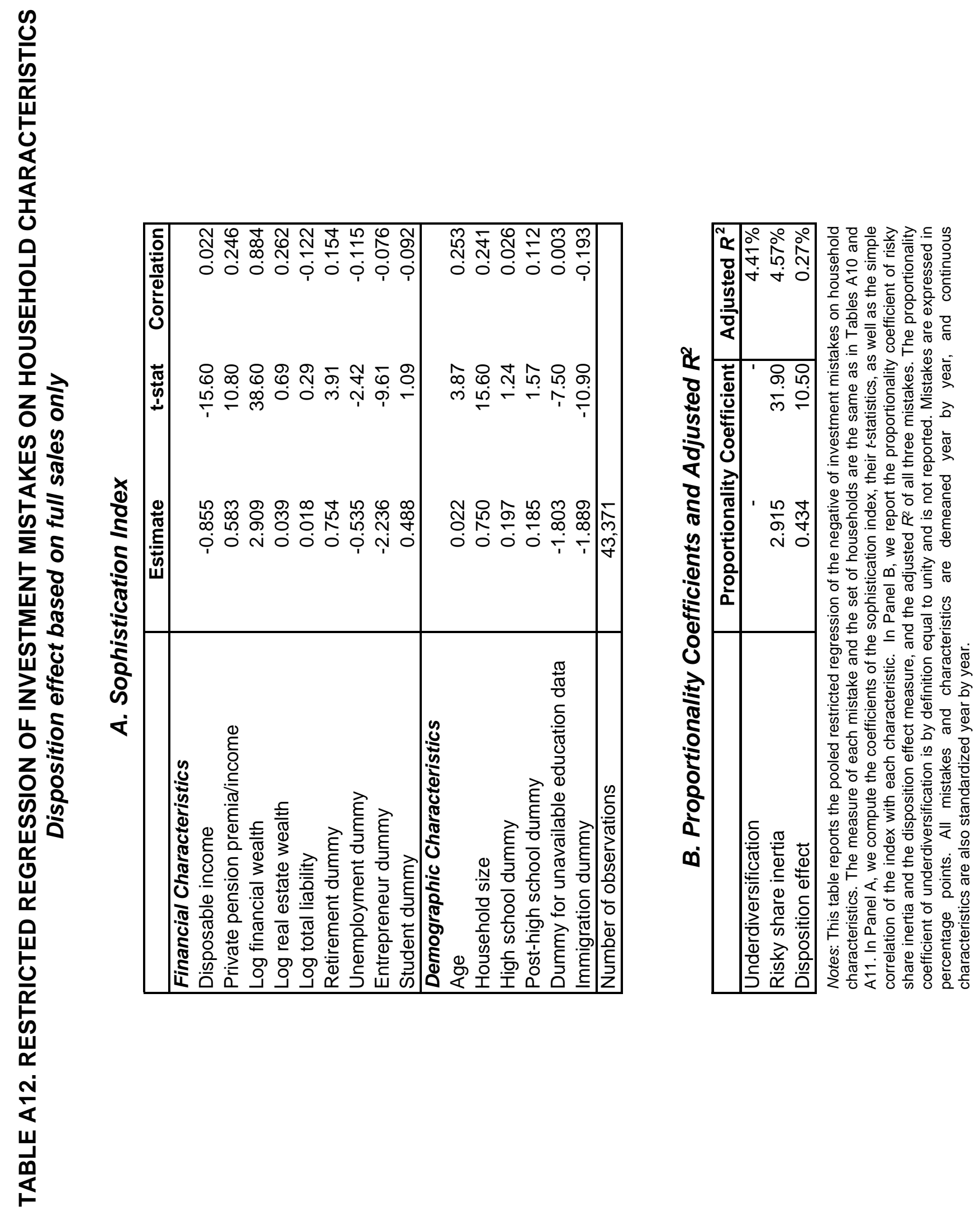




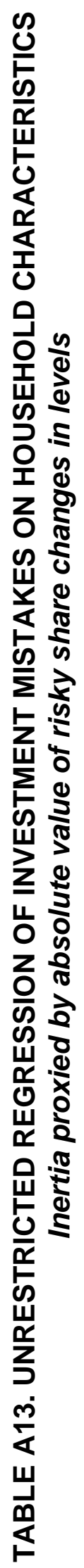

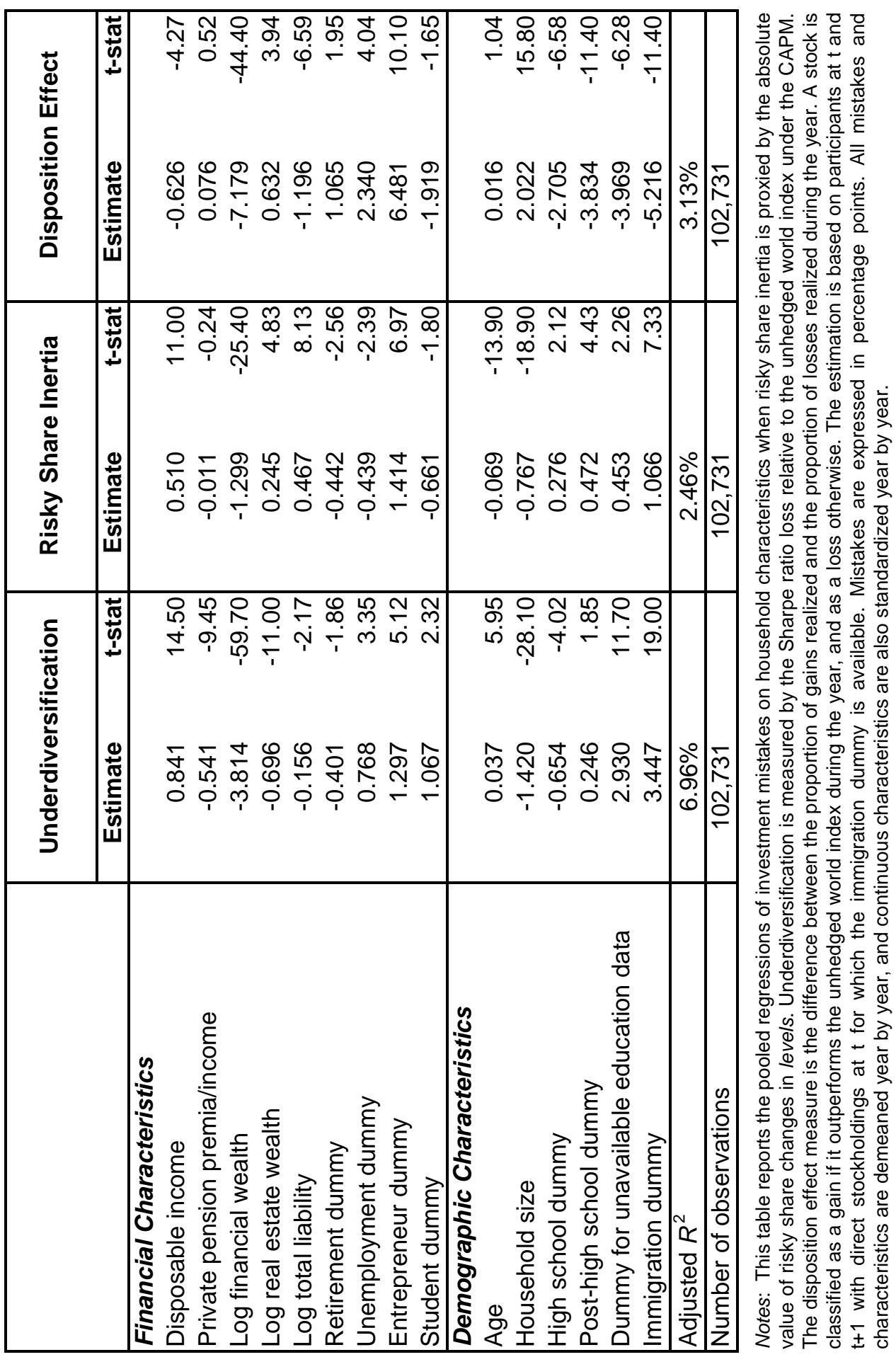




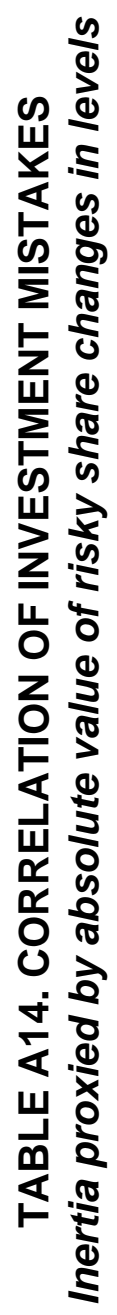

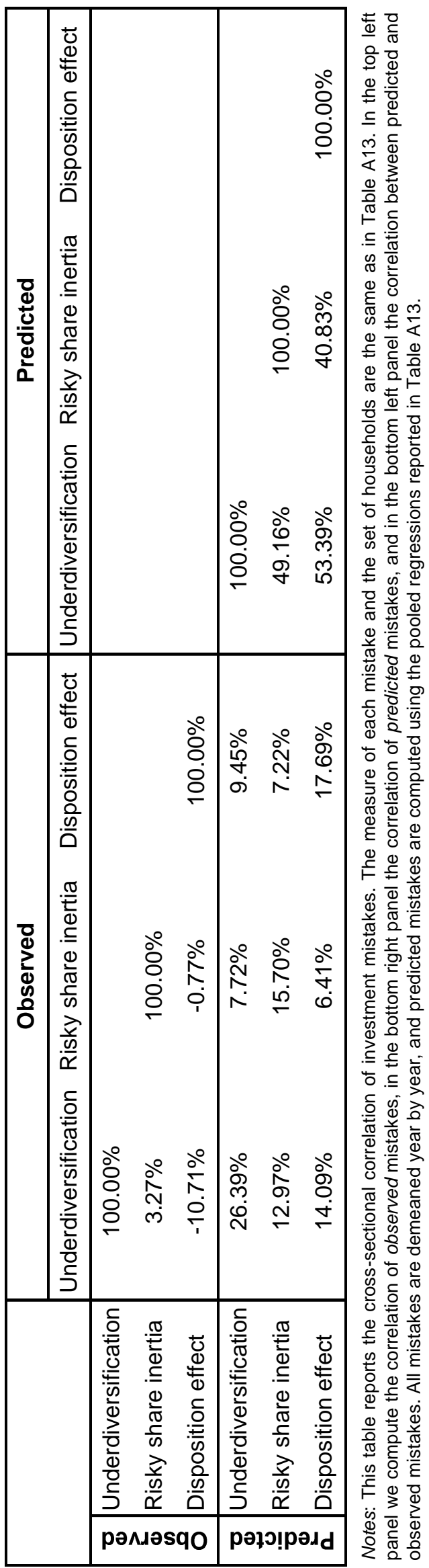




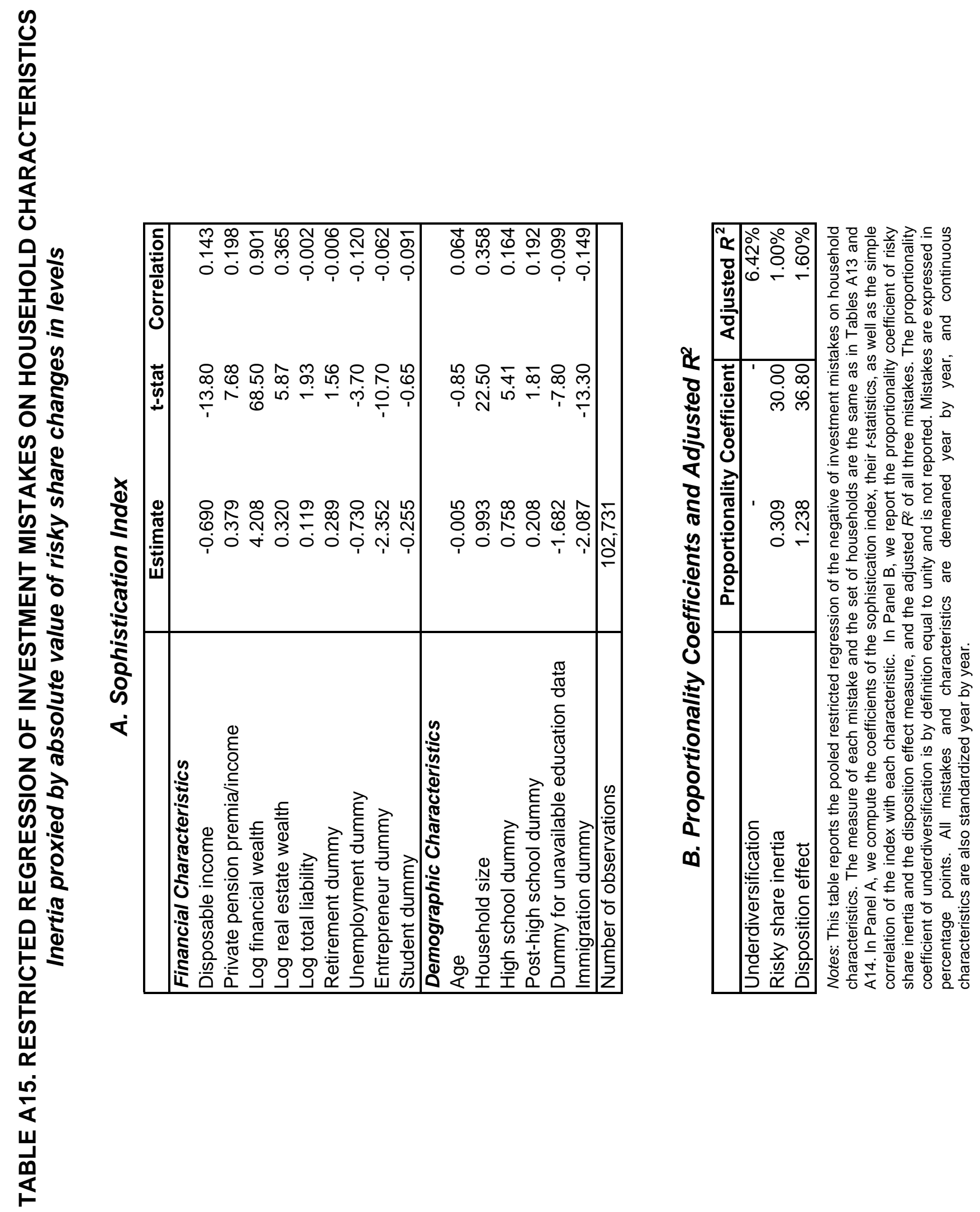



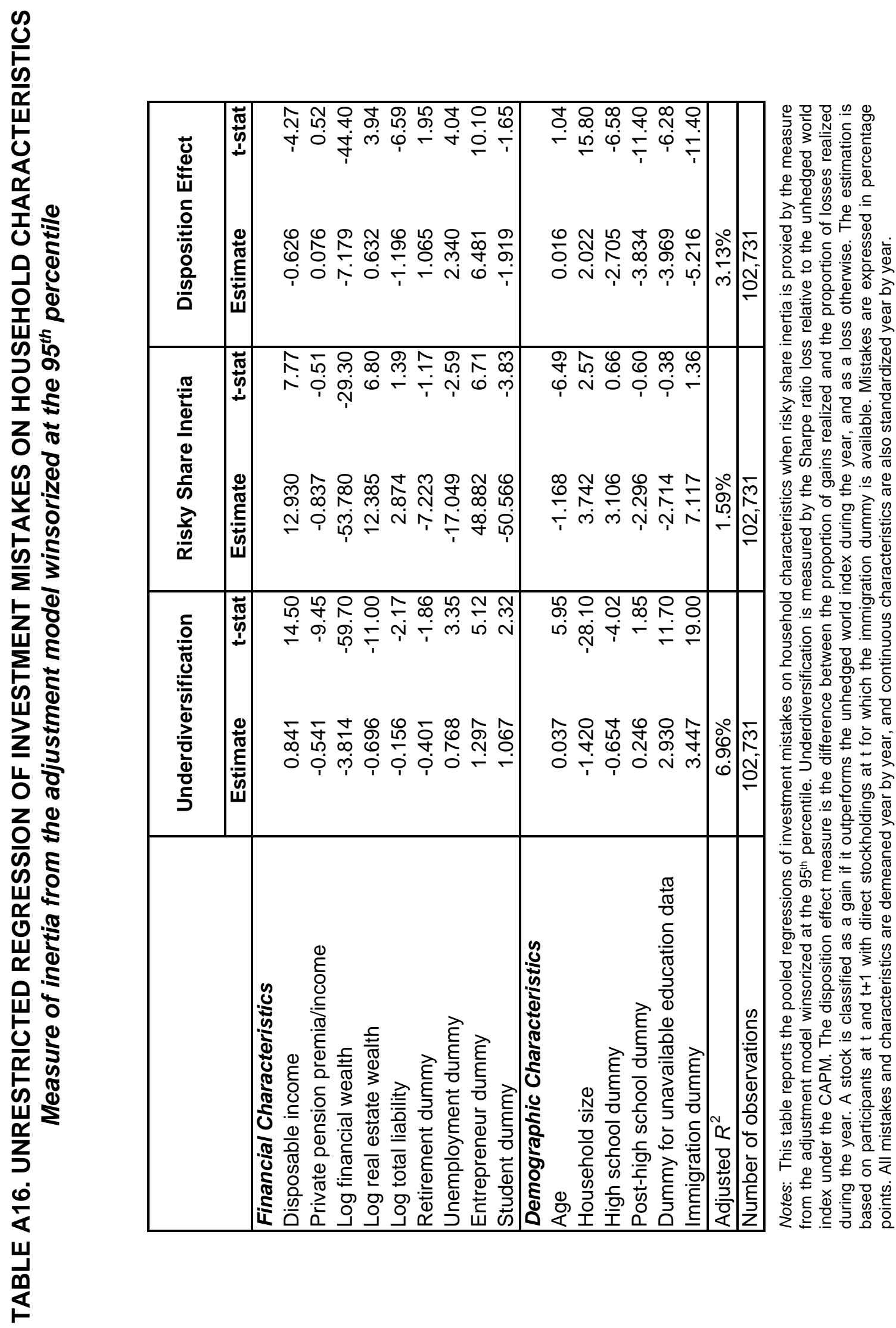


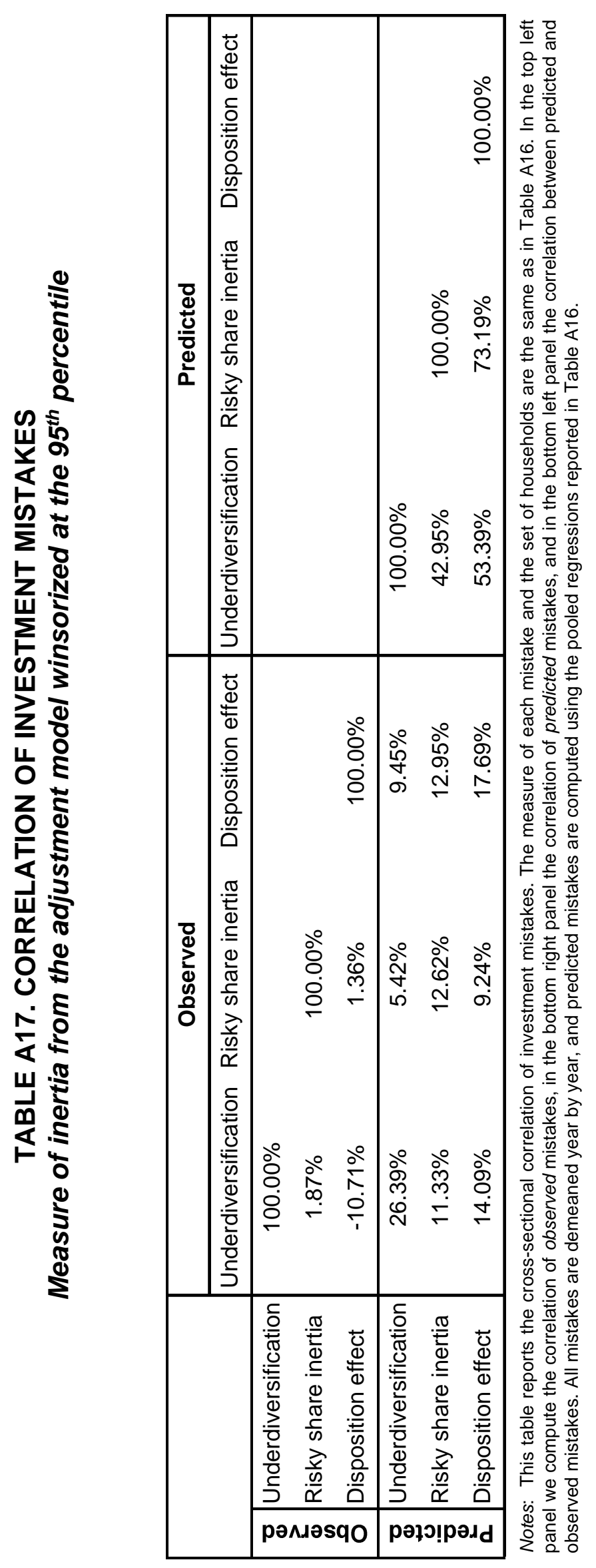




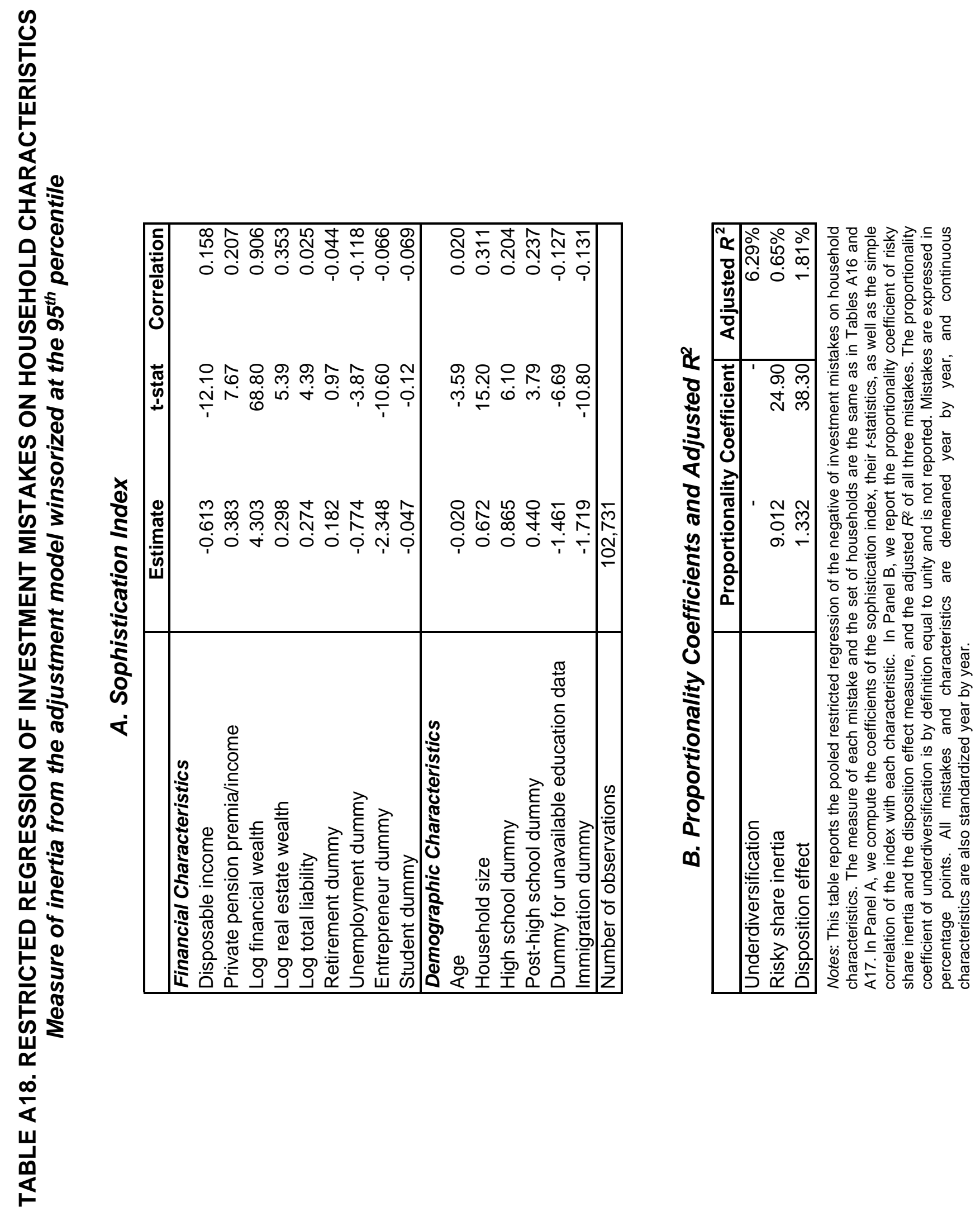



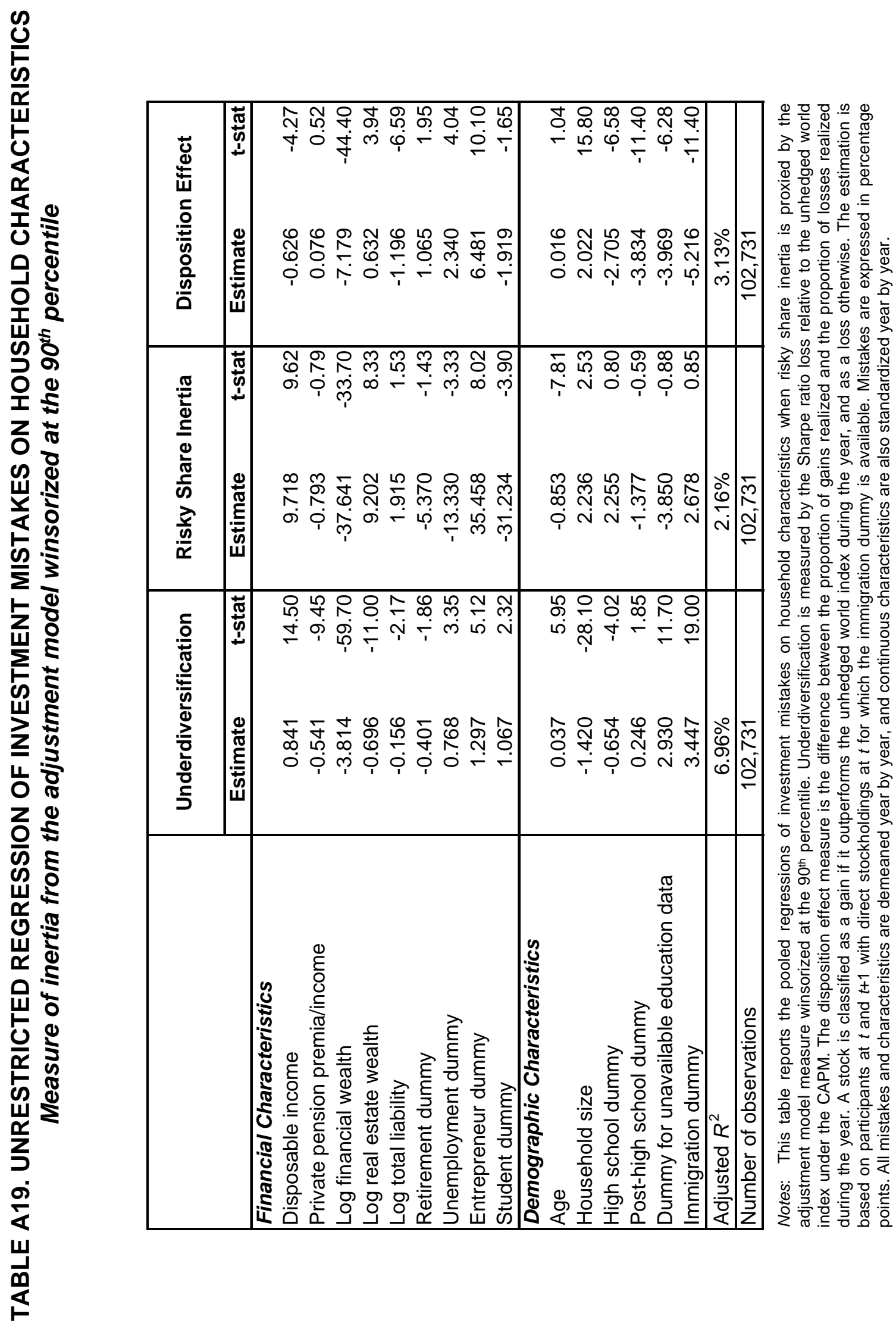


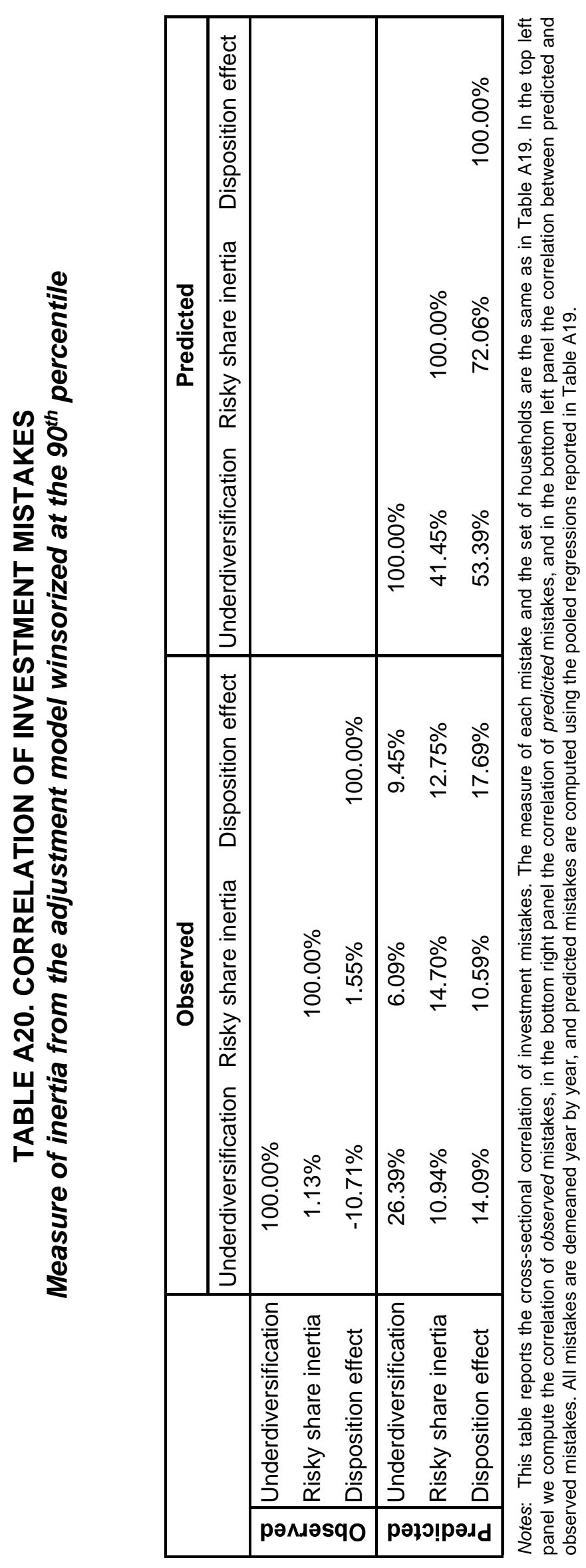




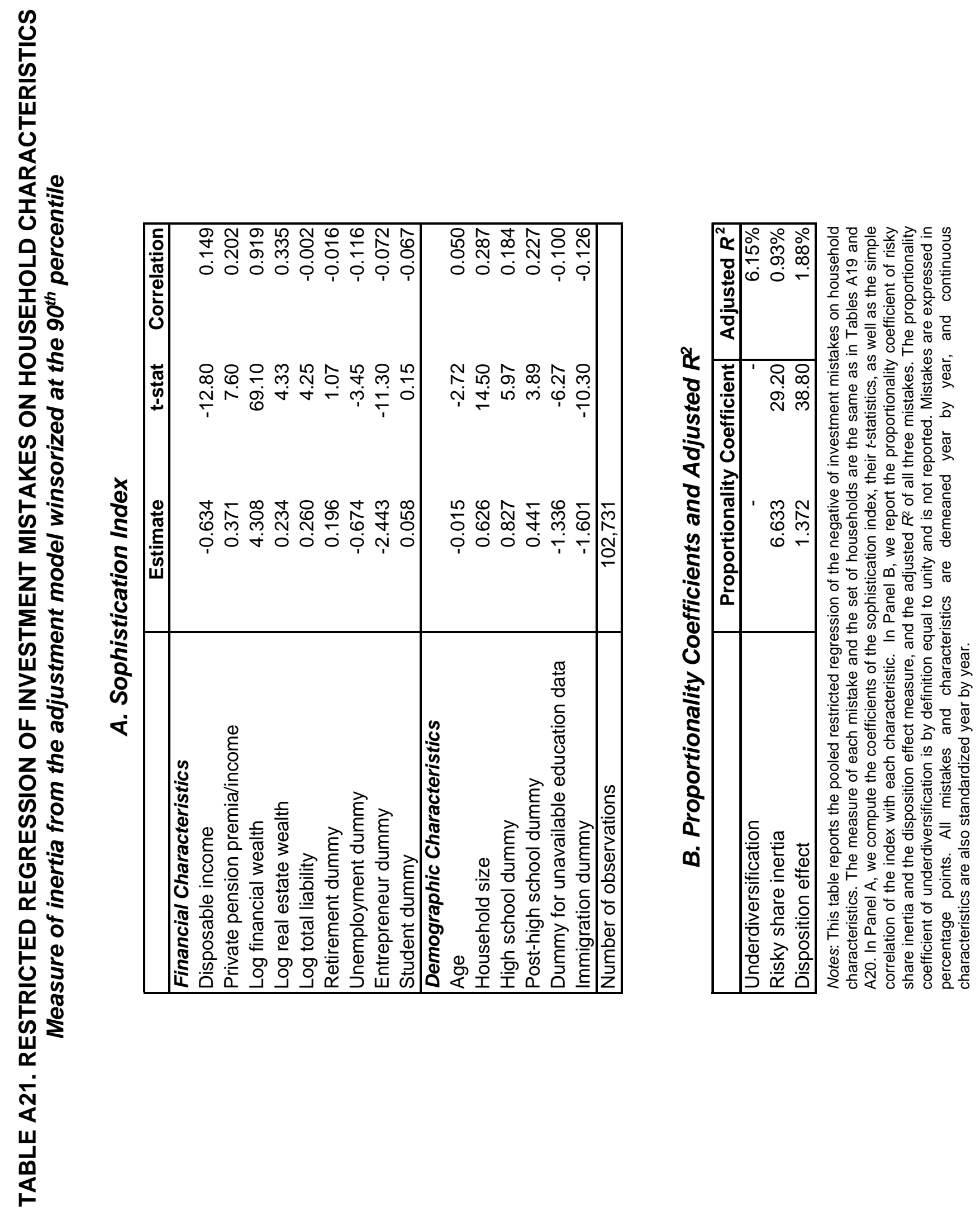




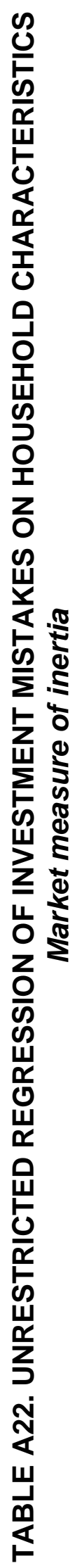

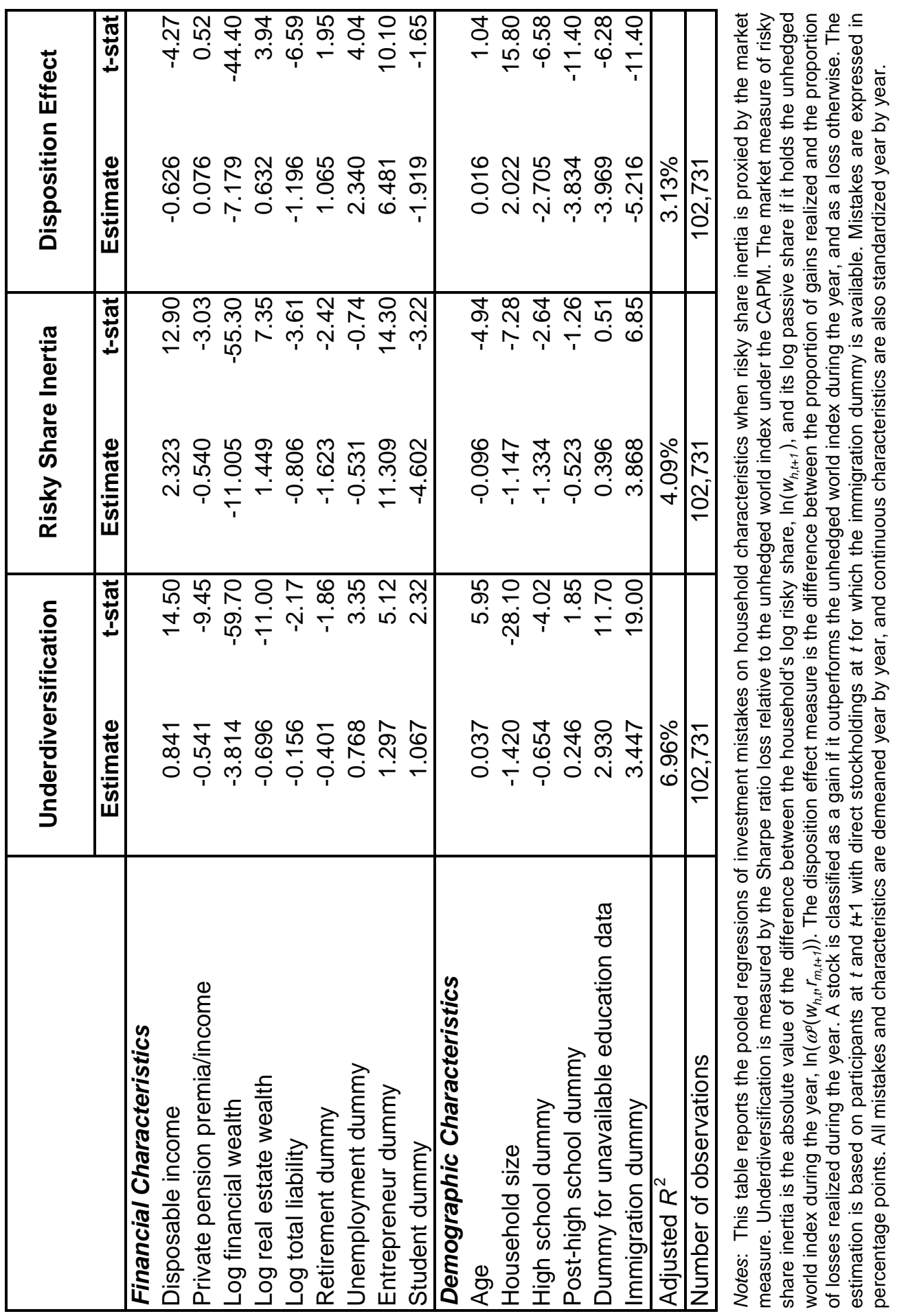




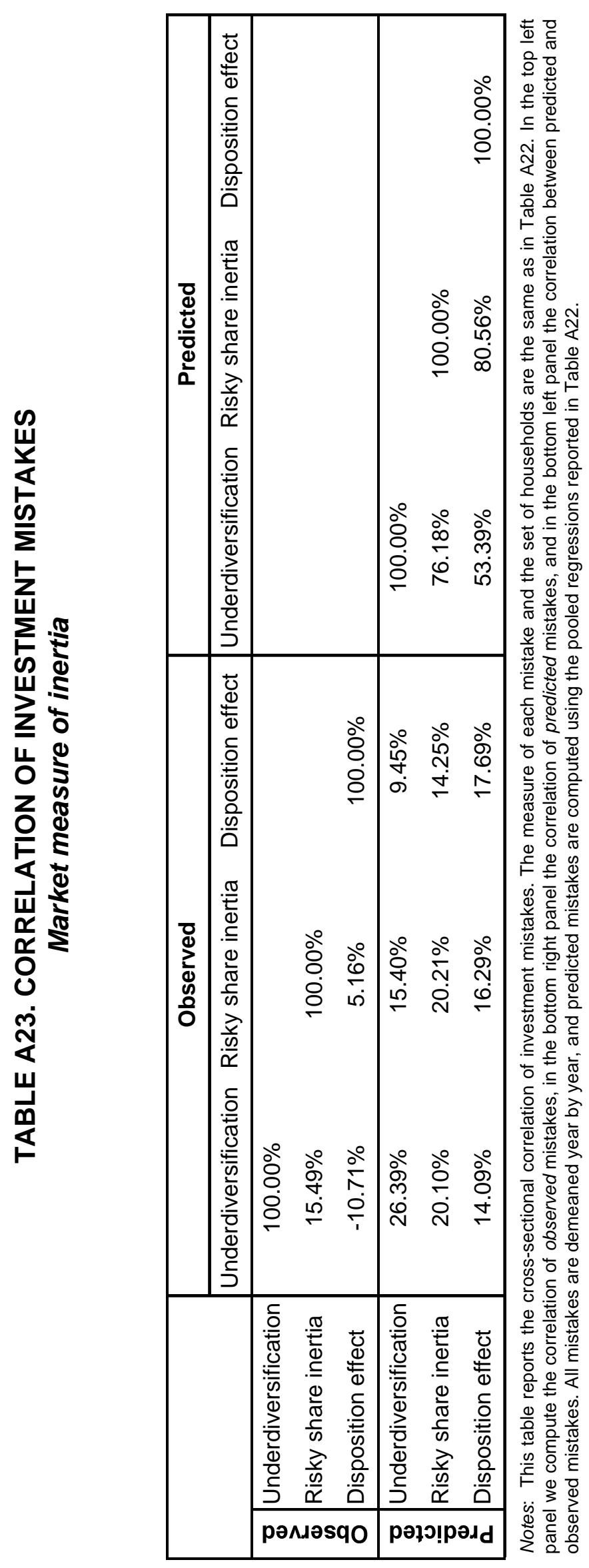




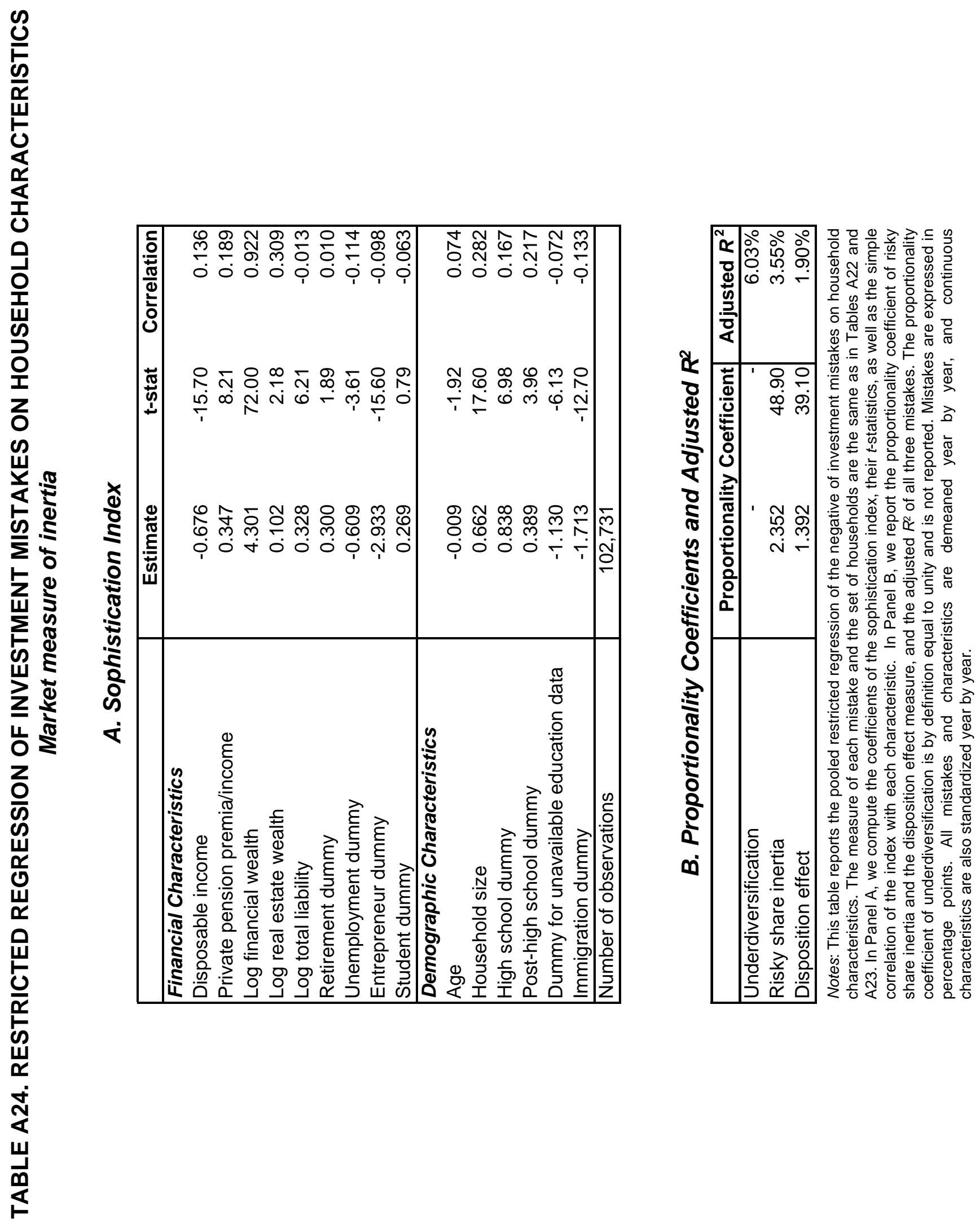



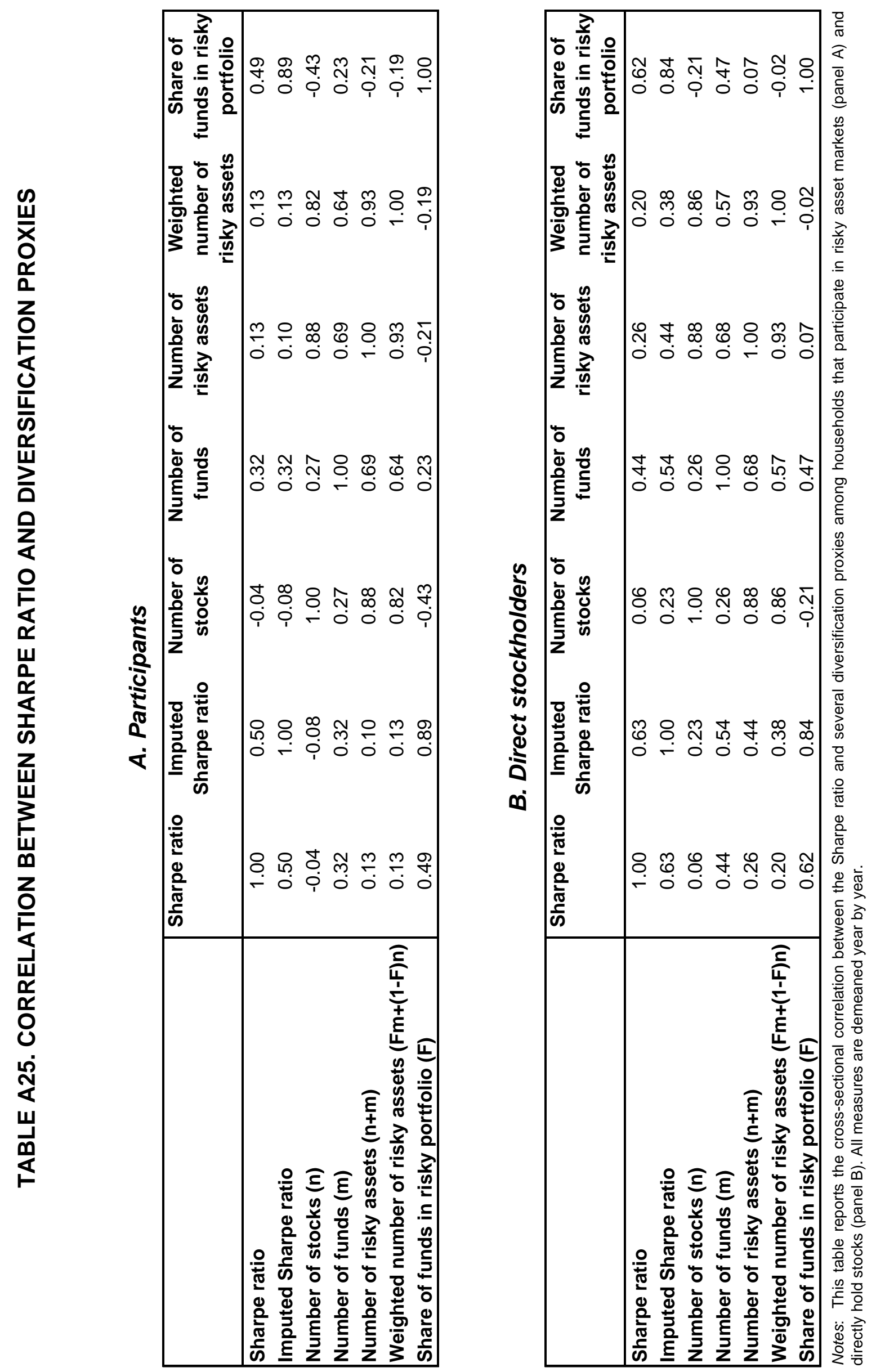

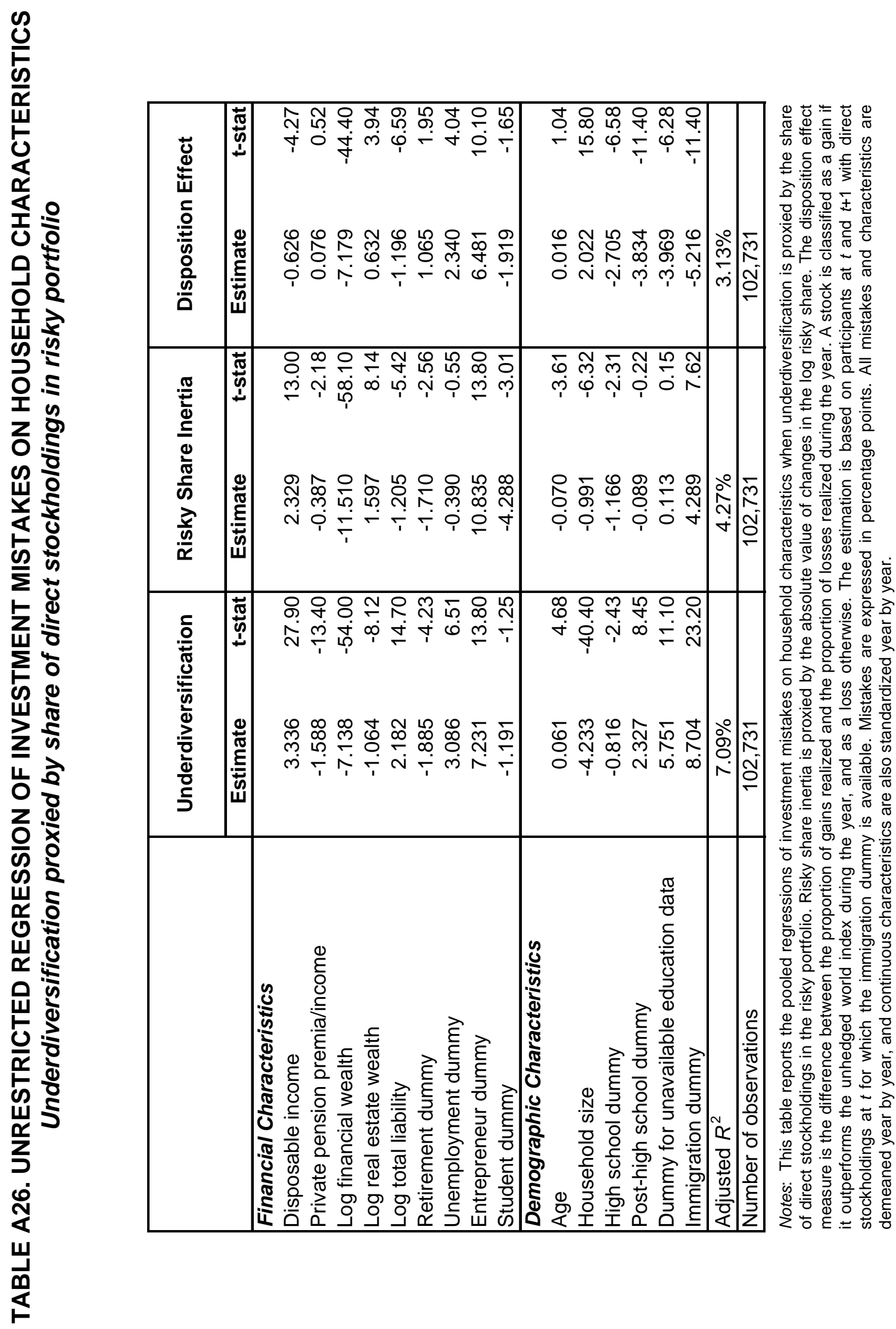


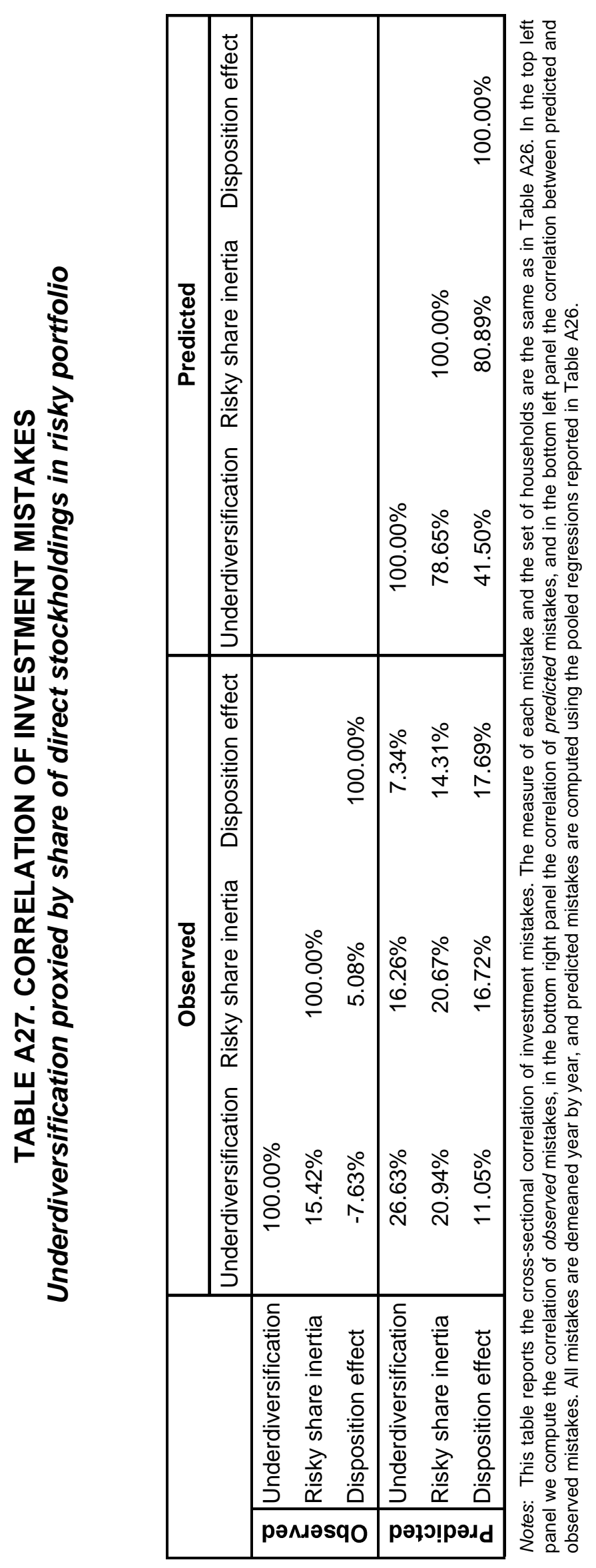




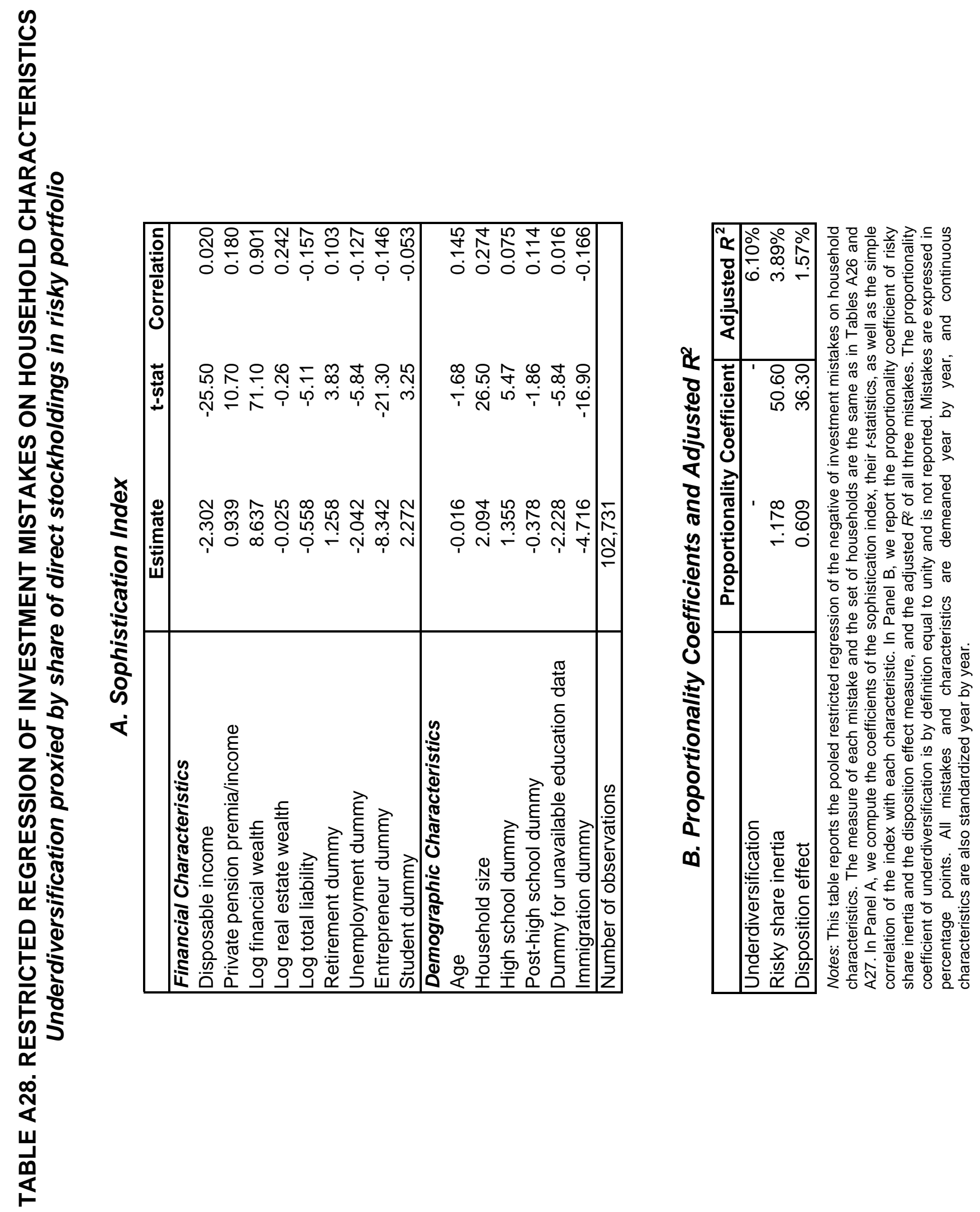




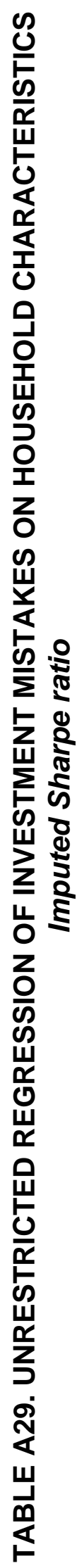

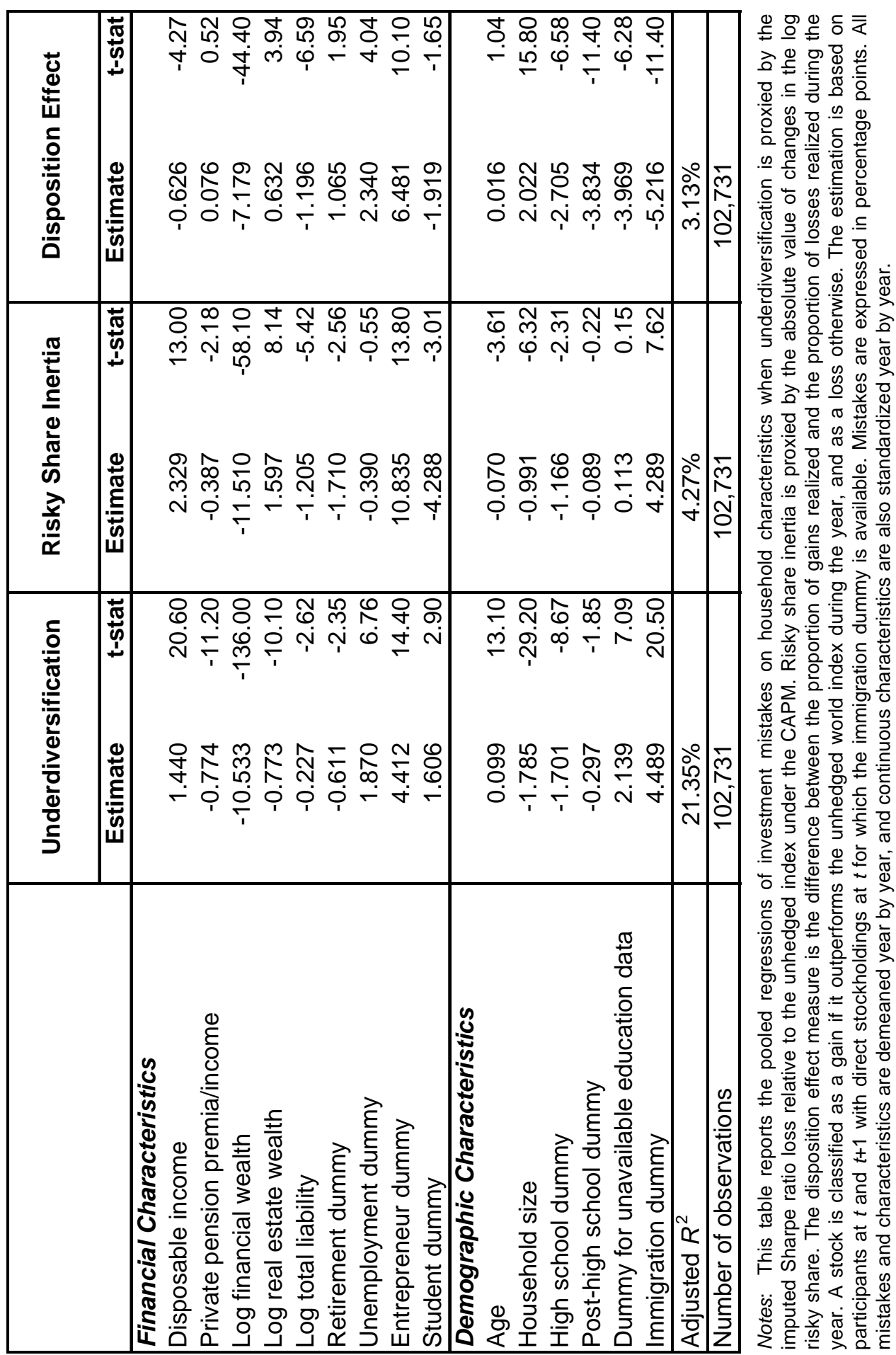




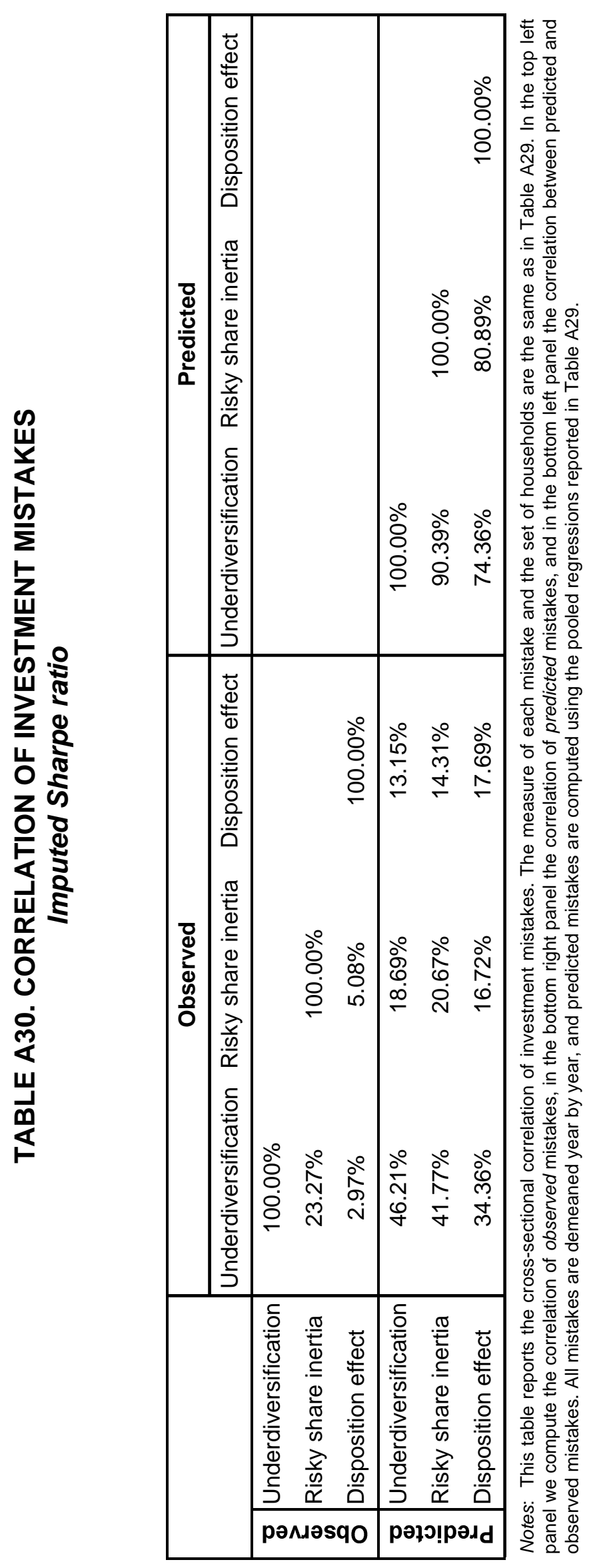




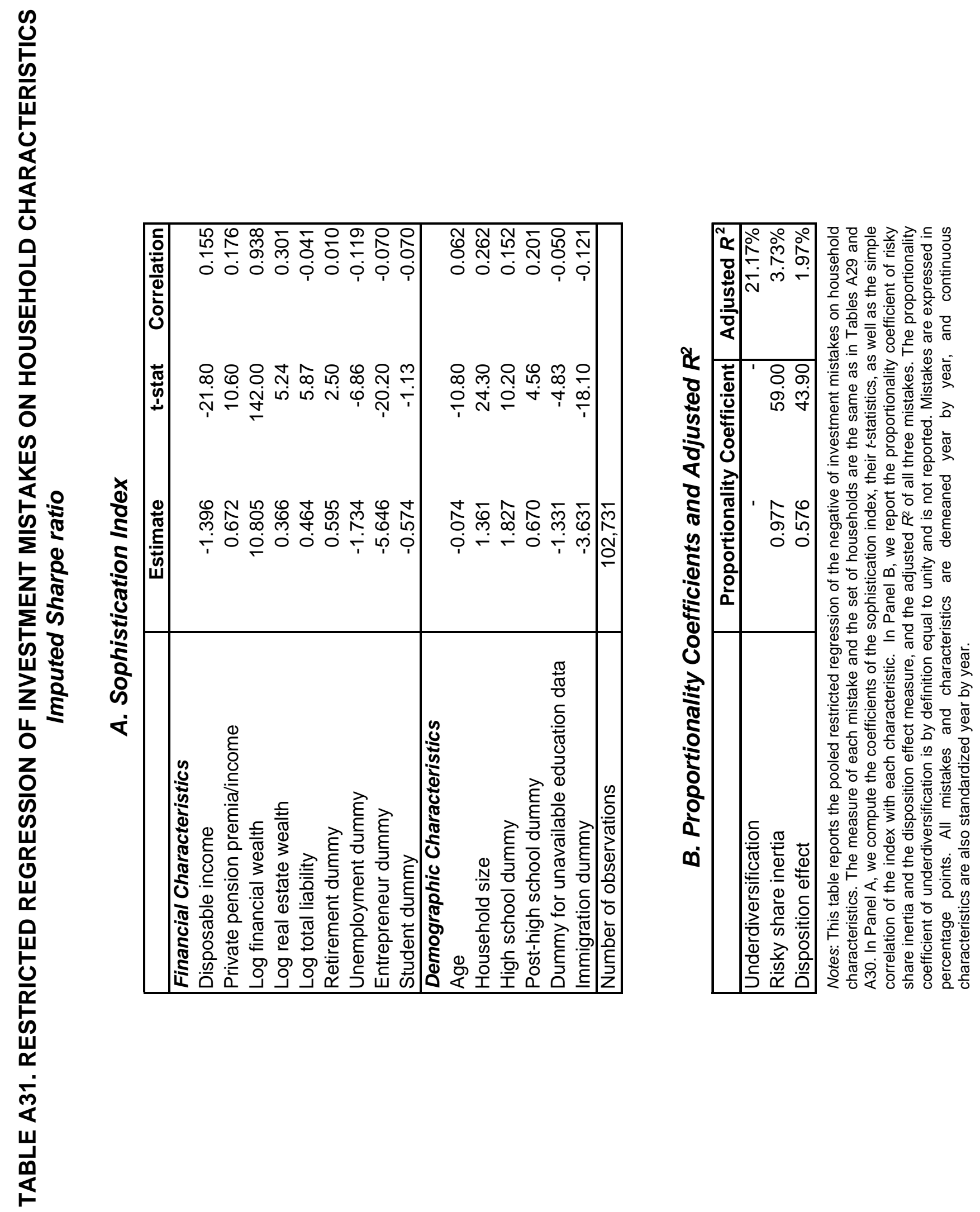

